\title{
The Future of Partisan Symmetry as a Judicial Test for Partisan Gerrymandering after LULAC v. Perry
}

\section{Citation}

Grofman, Bernard, and Gary King. 2007. The future of partisan symmetry as a judicial test for partisan gerrymandering after LULAC v. Perry. Election Law Journal 6(1): 2-35.

\section{Published Version}

doi:10.1089/elj.2006.6002

\section{Permanent link}

http://nrs.harvard.edu/urn-3:HUL.InstRepos:4214910

\section{Terms of Use}

This article was downloaded from Harvard University's DASH repository, and is made available under the terms and conditions applicable to Other Posted Material, as set forth at http:// nrs.harvard.edu/urn-3:HUL.InstRepos:dash.current.terms-of-use\#LAA

\section{Share Your Story}

The Harvard community has made this article openly available.

Please share how this access benefits you. Submit a story.

Accessibility 


\title{
The Future of Partisan Symmetry as a Judicial Test for Partisan Gerrymandering after LULAC v. Perry
}

\author{
BERNARD GROFMAN and GARY KING
}

\begin{abstract}
While the Supreme Court in Bandemer $v$. Davis found partisan gerrymandering to be justiciable, no challenged redistricting plan in the subsequent 20 years has been held unconstitutional on partisan grounds. Then, in Vieth $v$. Jubilerer, five justices concluded that some standard might be adopted in a future case, if a manageable rule could be found. When gerrymandering next came before the Court, in LULAC v. Perry, we along with two of our colleagues filed an Amicus Brief (King et al., 2005), proposing the test be based in part on the partisan symmetry standard. Although the issue was not resolved, our proposal was discussed and positively evaluated in three of the opinions, including the plurality opinion, and for the first time for any proposal the Court gave a clear indication that a future legal test for partisan gerrymandering will likely include partisan symmetry. A majority of Justices now appear to endorse the view that the measurement of partisan symmetry may be used in partisan gerrymandering claims as "a helpful (though certainly not talismanic) tool" (Justice Stevens, joined by Justice Breyer), provided one recognizes that "asymmetry alone is not a reliable measure of unconstitutional partisanship" and possibly that the standard would be applied only after at least one election has been held under the redistricting plan at issue (Justice
\end{abstract}

Bernard Grofman <http://www.socsci.uci.edu/ bgrofman/> is Professor of Political Science at the University of California, Irvine. The Supreme Court, as well as many lower federal courts, have cited his research on racial voting patterns and other topics related to elections on numerous occasions, perhaps most notably in Thornburg v. Gingles, 478 U.S. 30, 52-53 \& n. 20 (1986), one of the roughly twenty voting rights cases in nearly a dozen states where he has served as an expert witness. Grofman has also twice been a consultant to the Special Master in the Federal District Court, Southern District of New York, in cases where the failure of the legislator and governor to reach agreement forced the court to propose a congressional redistricting plan of its own for the State of New York.

Gary King < http://GKing.Harvard.edu $>$ is David Florence Professor of Government, and Director of the Institute for Quantitative Social Science, at Harvard University. The methods he and his coauthors developed are widely used by courts and experts in redistricting litigation. So that he and others could implement these methods, he wrote and freely distributes the software programs JudgeIt (along with Andrew Gelman), for measuring partisan bias and electoral responsiveness in districting plans, and EI, for measuring racially polarized voting from available electoral and census data. Both are widely used in academia, redistricting processes, and redistricting litigation. He has served as an expert witness or consultant in about a third of the U.S. states during their redistricting processes. He can be reached at 1737 Cambridge Street, Harvard University, Cambridge MA 02138; King@Harvard.Edu, 617-495-2027.

We are indebted to Justin Nelson for assistance with an Amicus Brief on Behalf of Neither Party which we submitted (along with Andrew Gelman and Jonathan Katz) to the U.S. Supreme Court in Jackson v. Perry, to Clover Behrend-Gethard for secretarial assistance in preparing this paper, and to the Library of Congress (PA\#NDP03-1), the National Science Foundation (SES-0318275, IIS-9874747), and the National Institutes of Aging (P01 AG17625-01) for research support. We are also indebted to Marshall Hurley Esq. for having provided us updated information on the rules for election of Superior Court judges in North Carolina. 
Kennedy, joined by Justices Souter and Ginsburg). We use this article to respond to the request of Justices Souter and Ginsburg that "further attention . . . be devoted to the administrability of such a criterion at all levels of redistricting and its review." Building on our previous scholarly work, our Amicus Brief, the observations of these five Justices, and a supporting consensus in the academic literature, we offer here a social science perspective on the conceptualization and measurement of partisan gerrymandering and the development of relevant legal rules based on what is effectively the Supreme Court's open invitation to lower courts to revisit these issues in the light of LULAC v. Perry.

\section{INTRODUCTION}

$\mathbf{T}$ HE U.S. Supreme Court declared partisan gerrymandering claims justiciable in Davis v. Bandemer, ${ }^{1}$ but in the subsequent two decades no redistricting plan has been struck down as an unconstitutional partisan gerrymander. In Vieth $v$. Jubilerer, ${ }^{2}$ five Justices concurred that the challenged Pennsylvania congressional plan was not, on the evidence before the Court, to be regarded as a partisan gerrymander, and four also asserted that, henceforth, partisan gerrymandering should be regarded as nonjusticiable. The four remaining Justices, who were in favor of further proceedings in the case, could not agree how to measure the severity of partisan gerrymandering or under what circumstances a plan was so egregious that it should be considered unconstitutional. The "swing" member on this case, Justice Kennedy, concurred on the merits of the decision finding the Pennsylvania congressional plan to be constitutional (asserting that the absence of agreed upon comprehensive and neutral principles for evaluation made it impossible to reach a judgment that the plan was unconstitutional), but opposed overturning Bandemer's holding that partisan gerrymandering was justiciable, in the hope that sometime in the future there might arise a clearly manageable standard that the Court could adopt.

In Spring 2006, the Supreme Court heard LULAC v. Perry, ${ }^{3}$ where it addressed, among other things, the legal claim that the 2003 re-redistricting of congressional lines in the State of Texas is an unconstitutional partisan gerrymander. ${ }^{4}$ The Court majority rejected two types of partisan gerrymandering claims: (1) that mid-decennial re-redistricting is inherently unconstitutional, and (2) that redistricting done for no motive other than partisan gain is in- herently unconstitutional. Even the combination of a mid-decadal re-redistricting and the absence of motivation other than partisan gain were held not to present a constitutional issue. ${ }^{5}$ However, though the 2003 Texas congressional plan was not found to be an unconstitutional partisan gerrymander, five members of the

1 Davis v. Bandemer, 478 U.S. 109 (1986).
2 Vieth v. Jubilerer, 541 U.S. 267 (2004).
${ }^{3}$ LULAC v. Perry, 126 S. Ct. $2594(2006)$. This case consolidated Nos. 05-204, 05-254, 05-276, and 05-439. It was decided on June 28, 2006.

4 The plan used for the 2002 congressional elections in Texas was a court-drawn plan whose constitutionality was upheld by the Supreme Court in Balderas v. Texas, 536 U.S. 919 (2002). When the 2002 elections resulted in a shift of the state into Republican control of both branches of the state legislature as well as control of the governorship, after much travail involving Democratic legislators who fled the state to break legislative quorum requirements, the Republican-controlled legislature passed a plan in 2003 which resulted in six additional Republican members of congress being elected in 2004. The near farcical elements of the initial Democratic attempts to prevent the Texas legislature from voting on that new congressional districting plan led one political satirist to characterize the situation after the 2004 congressional elections in Texas as: "For the Democrats, reredistricting temporarily delayed became reredistricting DeLayed, but never denied." (A Wuffle, personal communication, April 1, 2005). In Session v. Perry, 298 F. Supp. 2d 451 (E.D. Tex.) (three-judge court) (per curiam), summarily vacated sub nom. Jackson v. Perry, 543 U.S. 941 (2004), the District Court for the Eastern District of Texas, after hearing argument on this issue, said the 2003 Texas plan was not an unconstitutional gerrymander. (The District Court also rejected the claim that the plan violated Section 2 of the Voting Rights Act.) That decision was vacated and remanded to the District Court in the light of Vieth, 541 U.S. 941 (2004). After a reexamination of the political gerrymandering claims the District Court again held for the defendants in Henderson v. Perry, 399 F. Supp. 756 (2005), and that decision was appealed to the Supreme Court, on a variety of grounds, under the name LULAC v. Perry.

5 "The sole-intent standard . . . is no more compelling when it is linked to the circumstances that Plan $1374 \mathrm{C}$ is mid-decennial legislation." LULAC, 126 S. Ct. at 2602 (opn. of Kennedy, J.). 
Court reiterated the holding in Vieth that partisan gerrymandering can, in principle, be recognized as a violation of equal protection, and two others (Chief Justices Roberts and Justice Alito) took no position on that question. ${ }^{6}$

Although, "as in Vieth," there existed "no majority for any single criterion of impermissible gerrymander, ${ }^{\prime 7}$ this case marks a potential sea change in how the Supreme Court adjudicates partisan gerrymandering claims. For the first time, a criterion for detecting and measuring gerrymandering-known as partisan symmetry-attracted considerable positive attention by the Justices. The potential importance of the partisan symmetry criterion was argued for by us and two of our colleagues in an Amicus Brief submitted in that case (on behalf of neither party). ${ }^{8}$ The ideas in that Amicus Brief were discussed in three of the opinions, including the plurality opinion written by Justice Kennedy. ${ }^{9}$ A majority of Justices now appear to endorse our view that the measurement of partisan symmetry can be used as part of a broader test in resolving partisan gerrymandering claims. This case marks the first time that a majority of the Court has agreed on the potential use of any criterion for measuring the effects of partisan gerrymandering. (This of course merely recognizes current practice in many lower courts where the vast majority of experts routinely compute and often present results on the partisan fairness of redistricting plans based on the concept and measures of partisan symmetry we describe here.)

Two Justices (Stevens and Breyer) see it as "a helpful (though certainly not talismanic) tool."10 Speaking for himself alone, Justice Stevens identifies departure from partisan symmetry as one of eight criteria he would make use of in determining effects-based violations of equal protection in the context of partisan gerrymandering claims, ${ }^{11}$ and he explicitly finds that the challenged plan violates a partisan symmetry test. ${ }^{12}$ Moreover, Justice Stevens asserts that the "symmetry standard ... is undoubtedly 'a reliable standard' for measuring a 'burden ... on the complainants' representative rights.' "13

Two Justices (Souter and Ginsburg) look to the future and indicate that they "do not rule out the utility of a criterion of symmetry as a test."14 And most importantly, they explain that "interest in exploring this notion is evident [on the Court]."15

A fifth Justice, Justice Kennedy, also does not rule out use of this criterion, adding two caveats: that "asymmetry alone is not a reliable measure of unconstitutional partisanship" and that the Court may need to administer the standard retrospectively rather than prospectively. ${ }^{16}$ Justice Stevens characterizes Justice Kennedy's view as one of "leaving the door open to the use of the standard in future cases." 17

Furthermore, two additional justices, Chief Justice Roberts, joined by Justice Alito, while asserting that appellants have not yet provided "a reliable standard for identifying unconstitutional gerrymanders" ${ }^{\prime 18}$ leave open the question of an appropriate standard. ${ }^{19}$

${ }^{6}$ LULAC, 126 S. Ct. at 2652 (opn. of Roberts, C. J.).

7 LULAC, 126 S. Ct. at 2647 (opn. of Souter, J.).

${ }^{8}$ Amicus Brief in Jackson v. Perry Submitted on Behalf of Neither Party by Gary King, Bernard Grofman, Andrew Gelman, and Jonathan Katz in the U.S. Supreme Court (No. 05-276), henceforth King et al. (2005). See $<$ http://gking.harvard.edu/projects/red.shtml $>$.

${ }^{9}$ Although there was majority agreement on each of the issues raised in the case, those majorities were not always made up of the same set of Justices, and the case had six separate opinions.

${ }^{10}$ LULAC, 126 S. Ct. at 2638 (n.9) (opn. of Stevens, J. P., joined by Breyer, $S$ ).

${ }^{11}$ LULAC, 126 S.Ct. at 2641 (opn. of Stevens, J. P.).

12 "Plan 1374C [the challenged plan] is inconsistent with the symmetry standard . . ." (LULAC, 126 S. Ct. at 2637 (n. 8) (opn. of Stevens, J.).

${ }^{13}$ LULAC, 126 S. Ct. at 2637 (opn. of Stevens, J.), with internal quotes citing to ante (opinion of Kennedy, J.).

${ }^{14}$ LULAC, 126 S. Ct. at 2647 (opn. of Souter, J.).

${ }^{15}$ LULAC, 126 S. Ct. at 2647 (opn. of Souter, J.), with internal quotes citing to the opinion of Kennedy, J. and to the opinion of Stevens, J.

${ }^{16}$ LULAC, 126 S. Ct. at 2611 (opn. of Kennedy, J. joined by Justices Souter and Ginsburg), emphasis added.

${ }^{17}$ LULAC, 126 S. Ct. at 2638 (n.9) (opn. of Stevens, J.), with internal cite to opinion of Kennedy, J. See also Richard Briffault, LULAC on Partisan Gerrymandering: Some Clarity, More Uncertainty, 105 Mich. L. Rev. First Impressions 58,61 (2006).

${ }^{18}$ LULAC, 126 S. Ct. at 2651 (opn. of Roberts, C.J.), with internal cite quoting from the opinion by Kennedy, J., ante at 2612.

${ }^{19}$ Only Justice Scalia, joined by Justice Thomas, would vote to reverse Bandemer. These Justices reiterate their view in Vieth that, since "no party or judge has put forth a judicially manageable standard ... . we should simply dismiss appellants' claims as nonjusticiable." LULAC, 126 S. Ct. at 2663 (opn. of Scalia, J.). 
We find the openness of a majority of the Justices to making use of measures of partisan bias (a deviation from partisan symmetry) as part of a standard for unconstitutional partisan gerrymandering to be an extremely promising development for reining in abuses of gerrymandering in American democracy. ${ }^{20}$ We use this article to respond to the suggestion of Justices Souter and Breyer that "further attention ... be devoted to the administrability of such a criterion at all levels of redistricting and its review." ${ }^{21}$ In the process of so doing we comment on the three specific new ideas raised by Justice Kennedy's discussion in LULAC of possible tests for partisan gerrymandering: his suggestion that a "challenge could be litigated if and when the feared inequity arose" rather than on the basis of "unfair results that would occur in a hypothetical state of affairs;"22 his suggestion that we need to look comparatively to judge relative magnitudes of partisan bias in alternative plans (an idea which parallels how courts have investigated ill-compactness claims based on state constitutional challenges), and his specific suggestion to distinguish the case where a majority party has its voting strength exaggerated (which is how he characterizes the 2003 plan, based on the actual results in 2004, with the Republicans as the majority party) from the case where a party that is in the process of becoming a minority in terms of voting support uses redistricting to entrench itself in power over the remainder of the decade (which is how he characterizes the 1991 Texas congressional plan, with the Democrats seen as a once dominant party which loses voter support over the course of the decade). ${ }^{23}$

We also address the concerns of Justice Kennedy and other Justices that a partisan symmetry test can only be effectively used if there is a specified threshold to distinguish unconstitutional gerrymandering from mere politics as usual. ${ }^{24}$ But we share the view of Justice Stevens that, even if the Court fully adopts the concept of partisan symmetry as one that is legally relevant, and recognizes the potential usefulness of the specific methodology that can be used to measure levels of partisan bias that we discuss below and in our previous writings, it is for the Court to make the critical judgments about what would constitute unconstitutional- ity or legally actionable thresholds and standards: "Justice Kennedy faults proponents of the symmetry standard for 'not providing a standard for deciding how much partisan bias is too much' (ante at 13). But it is this Court, not proponents of the symmetry standard, that has the judicial obligation to answer the question of how much unfairness is too much." 25 Although we believe that the choice of legally actionable thresholds for violations of partisan symmetry is the Court's purview, social scientists can be helpful by clarifying the logical possibilities-which we also do here.

The remainder of this article consists of four parts: In Section II we expand and clarify the arguments laid out in King et al. (2005) as to the potential usefulness of the measurement of partisan symmetry, and we identify and rebut a number of common misconceptions about the partisan symmetry standard, most of which are given airing in various of the briefs filed in LULAC. Then, in Section III, we consider ways

20 The consequences of partisan gerrymandering are arguably exacerbated in situations of razor thin legislative majorities and high ideological polarization. (See B. Grofman and G. Jacobson, Amicus Brief in Richard Vieth, et al., v. Robert C. Jubelirer, et al., 541 U.S. 267 (2004); S. Hirsch, The United States House of Unrepresentative: What Went Wrong in the Latest Round of Congressional Redistricting, 2 Election Law Journal 179-216 (2003).

${ }^{21}$ LULAC, 126 S. Ct. at 2647 (opn. of Souter, J.). We also note that, in Justice Stevens' view, "Part III of the Court's opinion and ... my own opinion demonstrate [that] assessing whether a redistricting map has a discriminatory impact on the opportunities for voters and candidates of a particular party to influence the political process is a manageable judicial task." LULAC, 126 S. Ct. at 2636 (n. 5) (opn. of Stevens J.).

22 LULAC, 126 S. Ct. at 2611 (opn. of Kennedy, J.).

${ }^{23}$ In Justice Kennedy's view: "A test that treats these similarly effective power plays in such different ways does not have the reliability that appellants ascribe to it." LULAC, 126 S. Ct. at 2610 (opn. of Kennedy J.).

${ }^{24}$ However, while this article is directly relevant to the empirical questions posed by this case related to partisan gerrymandering - in particular to the conceptualization and measurement of partisan bias-since we have not fully reviewed the evidentiary record nor conducted independent empirical investigations of our own, we expressed in our Brief and express here no views about the level of partisan bias in the redistricting plan that was at issue nor that in previous plans, nor do we express an opinion as to which party ought to have prevailed in $L U$ $L A C$ with respect to the issue of unconstitutional partisan gerrymandering.

${ }^{25}$ LULAC, 126 S. Ct. at 2638 (n. 9) (opn. Kennedy, J.). 
in which courts might address the issue of setting a prima facie legal threshold for when the level of partisan gerrymandering rises to a matter of legal concern-so as to distinguish egregious and unconstitutional gerrymandering from politics as usual. Next, in Section IV, we consider how partisan symmetry can be made a component of a broader multi-criteria standard for partisan gerrymandering that deals with both overall equal protection and matters specific to particular districts. ${ }^{26}$ Finally, in Section V, we provide a concluding discussion that looks to the future of partisan gerrymandering claims.

\section{CONCEPTUALIZING AND MEASURING PARTISAN FAIRNESS}

We now explain the concept of partisan symmetry as a standard for partisan fairness, and then the measurement of how redistricting plans may deviate from this fairness standard. We also discuss whether measures of partisan fairness should be imposed prospectively, before an election is held under a redistricting plan, or retrospectively, and finally we clarify some common misunderstandings about partisan symmetry.

\section{Conceptualization}

As we wrote in King et al., "The symmetry standard requires that the electoral system treat similarly-situated parties equally, so that each receives the same fraction of legislative seats for a particular vote percentage as the other party would receive if it had received the same percentage [of the vote]."27 Social scientists have long recognized partisan symmetry as the appropriate way to define partisan fairness in the American system of plurality-based elections, ${ }^{28}$ and for many years such a view has been virtually a consensus position of the scholarly community. We are aware of no published disagreement or even clear misunderstanding in the scholarly community about partisan symmetry as a standard for partisan fairness in plurality-based American elections since the clarification and measures introduced by Gary King and Robert X. Browning in Democratic Representation and Partisan Bias in Congressional Elections. ${ }^{29}$ This level of consensus is explicitly acknowledged by Justice Stevens, who writes in his opinion in LULAC that "this standard is widely accepted by scholars as providing a measure of partisan fairness in electoral systems." ${ }^{30}$ Indeed, as Justice Stevens pointed out,

${ }^{26}$ Such a standard can satisfy the desire of the plurality in Davis v. Bandemer, 478 U.S. 109 (1986), for "a showing of more than a de minimis effect" (at 134) such that "an actual or projected history of disproportionate results exists, and that the electoral system is arranged in a manner that will consistently degrade a voter's or a group of voters' influence on the political process as a whole." (at 132). In the language of Justice Kennedy in LULAC, it must "show a burden, as measured by a reliable standard, on the complainants' representational rights." (at 2602) (opn.of Kennedy, J.).

27 2005, 4-5; op cit.; quoted in LULAC, 126 S. Ct. at 2637 (opn. of Stevens, J.).

${ }_{28}$ Although the literature on the fair translation of seats into votes can be traced back more than a century, the most prominent early studies in the modern literature include Edward R. Tufte, The Relationship Between Seats and Votes in Two-Party Systems, 67 Am. Pol. Sci. Rev. 540-554 (1973), and Bernard Grofman, Measures of Bias and Proportionality in Seats-Votes Relationships, 9 Political Methodology 295-327 (1983).

2981 Am. Pol. Sci. Rev. 1251 (1987).

${ }^{30}$ Justice Stevens then cites (at pp. 21-22) to a number of the references given in King et al. (2005) in support of this proposition, including Edward R. Tufte, The Relationship Between Seats and Votes in Two-Party Systems, 67 Am. Pol. Sci. Rev. 540-554 (1973); Gary King and Robert X. Browning, Democratic Representation and Partisan Bias in Congressional Elections, 81 Am. Pol. Sci. Rev. 1251 (1987); Andrew Gelman \& Gary King, A Unified Method of Evaluating Electoral Systems and Redistricting Plans, 38 Am. J. Pol. Sci. 514 (1994); Dennis Thompson, Election Time: Normative Implications of Temporal Properties of the Electoral Process in the United States, 98, Am. Pol. Sci. Rev. 51 (2004); and Erik J. Engstrom \& Samuel Kernell, Manufactured Responsiveness: The Impact of State Electoral Laws on Unified Party Control of the Presidency and House of Representatives, 1840-1940, 49 Am. J. Pol. Sci. 531 (2005). As explained elsewhere, "[s]cholars have reached near consensus on partisan symmetry as a standard of partisan fairness and have made great progress on developing measures that can be used to see whether electoral systems and districting plans meet this standard." Gary King, John Bruce \& Andrew Gelman, "Racial Fairness in Legislative Redistricting," in Classifying by Race 85, 85 (Paul E. Peterson, ed., 1996). There are many other references we could give (see e.g., Ernesto Calvo \& Maria Victoria Murillo, Who Delivers? Partisan Clients in the Argentine Electoral Market, 48 Am. J. Pol. Sci. 742 (2004); and Thomas W. Gilligan \& John G. Matsusaka, Structural Constraints On Partisan Bias Under The Efficient Gerrymander, 100 Pub. Choice 65, (1999)) to further support this claim. The only alternative standard of fairness that exists in the political science literature is proportionality of seats and votes, but it is widely recognized that a proportionality standard is simply not appropriate for use as a legal standard in plurality based elections, since plurality elections cannot be expected to yield proportional results. 
"the symmetry standard was not simply proposed by an amicus to the Court [in LULAC], it was also used by the expert for plaintiffs and the expert for the state in assessing the degree of partisan bias in Plans 1151C [the 2001 Balderas court-drawn plan] and Plan 1374C [the 2003 plan under challenge]." ${ }^{31}$ Moreover, neutral officials such as courts and non-partisan members of redistricting commissions have also regularly made use of it. ${ }^{32}$

The concept of partisan symmetry is broadly applicable, in that it applies not only to twoparty legislative elections, but also to multiparty systems, ${ }^{33}$ and even non-legislative elections. ${ }^{34}$ For simplicity of exposition, however, we focus here only on the simple and important case of two-party (Democratic and Republican) contests in single-member, plurality winner legislative districts.

For the purpose of this article, we define an electoral system as a set of specific legal rules that govern an election-such as winning by plurality, who has the franchise, where the voting machines are located, etc.-as well as the legislative districting plan. ${ }^{35}$ The key to the symmetry definition of fairness is that it evaluates the electoral system as a whole by evaluating how voter preferences statewide are translated into the division of legislative seats between the parties. It is also a simple and direct generalization of the symmetry standard universally applied to candidates in winnertake-all plurality elections in individual singlemember legislative districts. We explain the definition of fairness in this simple single-district context first and then discuss the generalization that works for collections of districts in evaluating entire state electoral systems in the context of redistricting.

The electoral rule in the simple context of a single member legislative district is that whichever candidate receives a plurality of the votes wins the legislative seat. It is important to recognize that this obvious definition of fairness requires no knowledge of the vote outcome or who actually will win the election; rather it evaluates fairness by setting rules for allocating all possible vote outcomes to seat outcomes, and refers to candidates only by their vote totals and not by their names or attributes. In particular, the reason it is considered fair for one candidate to win the seat if he or she wins a plurality of the votes is not because of what happened in the election, but rather because of what would happen under the symmetric but opposite hypothetical outcome: if the other candidate had received a plurality of votes instead, he or she would win the seat. An unfair system would be one where we know the opposite hypothetical would not occur.

Thus, the symmetry standard in this case merely involves the comparison of one hypothetical outcome to another. Fairness is defined in this context by each party's candidate being treated equally under the law by rules that provide an equal opportunity to compete for the seat. Symmetry is thus a way of ensuring "anonymity," the fairness criterion that prevents electoral system rules from referring to political parties by name rather than in terms of how many votes they receive in the election.

${ }^{31}$ LULAC, 126 S. Ct. at 2637 (opn. Stevens J.), citing to App. 34-42 (report of Professor John R. Alford, expert for Appellants), and id. at 189-193, 216 (report of Professor Ronald Keith Gaddie, expert for the State). Here we would call special attention to Graph 2 in the Alford report, and Fig. 1 in the Gaddie Report.

${ }^{32}$ See, e.g., Page v. Bartels, 144 F. Supp. 2d 346 (D.N.J. 2000). However, many uses of seats-votes curves by courts and redistricting commissions do not take advantage of the most recent methodological improvements in evaluating partisan symmetry found in the political science literature. (See below.)

${ }^{33}$ See, e.g., Gary King, Electoral Responsiveness and Partisan Bias in Multiparty Democracies, 15 Legislative Studies Quarterly, 159, 163-65, 181 (1990).

${ }^{34}$ For example, partisan symmetry, and associated measures, have been applied to the Electoral College (Andrew Gelman, Jonathan Katz, and Gary King, "Empirically Evaluating the Electoral College," Chapter 5, pp. 75-88, in Ann N. Criegler, Marion R. Just, and Edward J. McCaffery, eds., Rethinking the Vote: The Politics and Prospects of American Electoral Reform, (New York: Oxford University Press, 2004, <http://gking.harvard.edu/files/abs/ rethink-abs.shtml>); Bernard Grofman, Thomas Brunell, Janet Campagna, Distinguishing Between the Effects of Swing Ratio and Bias on Outcomes in the U.S. Electoral College, 1900-1992, 16(4) Electoral Studies 471-487 (1997); and to delegate selection in presidential election nomination contests (Stephen Ansolabehere and Gary King, Measuring the Consequences of Delegate Selection Rules in Presidential Nominations, 52(2) Journal of Politics 609-621 (May, 1990), $<$ http://gking.harvard.edu/files/abs/pri-abs.shtml $>$.

${ }^{35}$ For a more general discussion of the various types of electoral laws, see Bernard Grofman and Arend Lijphart (eds.), "Introduction," in Electoral Laws and Their Political Consequences, esp. pp. 1-3 (New York: Agathon Press, 1986). 
Anonymity is ensured by partisan symmetry since if we take an electoral result and switch the names of the parties that received the particular vote outcomes, the seat outcomes would also switch.

This basic symmetry definition given above is applicable to each individual district in all single-member, plurality winner, district-based legislative election contests in the U.S. Any electoral rule that would require one candidate in a district to garner more votes to win than another candidate, or which refers to the names or attributes of the candidates in deciding the winner would obviously not last long in any U.S. court with appropriate jurisdiction. The rule is also a clear reflection of fundamental tenets of American representative democracy and culture.

The definition of partisan symmetry in the context of redistricting takes this same venerable principle and slightly generalizes it to apply to the relevant group of districts, such as an entire state legislature or all the congressional districts within a state. For this group of districts, the symmetry standard requires that the number of seats one party would receive if it garnered a particular percentage of the vote be identical to the number of seats the other party would receive if it had received the same percentage of the vote, or in other words that outcomes not depend upon party names. For example, suppose the Democratic Party receives an average of $55 \%$ of the vote totals in a state's legislative district elections and, because of the way the district lines were drawn, it wins $70 \%$ of the legislative seats in that state. Is that fair? That question cannot be answered based on this one piece of evidence alone. It depends on a comparison with the opposite hypothetical outcome: It would be fair only if the Republican Party would also have received $70 \%$ of the seats in an election where it had received an average of $55 \%$ of the vote totals in district elections. This electoral system would be biased against the Republican Party if it would garner fewer than $70 \%$ of the seats and biased against the Democratic Party if the Republicans would garner more than $70 \%$. In other words, partisan symmetry requires that "each political group in a State has the same chance to elect representatives of its choice as any other political group." 36
The key idea is that candidates of each political party should have equal opportunity in translating voter support into the division of legislative seats between the parties: as we noted previously, symmetry requires that the electoral system treat similarly-situated political parties equally. Partisan symmetry says nothing about which candidates should be elected, and it is not conditioned on any particular vote division: it only says that if a party is able to muster a certain fraction of votes, then it should get the same number of seats as the other party would if that party had received the same voter support. Symmetry thus evaluates partisan gerrymandering only by its consequences.

Other features of the electoral system that have sometimes been used as proxies for partisan gerrymandering are only relevant to this definition insofar as they affect the partisan symmetry of the electoral system. These other factors-such as who drew the district lines, whether there was proper citizen input, or whether the districts are compact, split local political subdivisions, or maintain communities of interest-may in fact be of interest to courts or to the legislature for other reasons, or as values in and of themselves, but in terms of fairness to political parties, they are only relevant under this standard if they have an effect on making the electoral system deviate from partisan symmetry. (Of course, the Court may also wish to require some of these other criteria to hold as well.)

Measuring symmetry and partisan bias does not require "proportional representation" (where each party receives the same proportion of seats as it receives in votes). Of course, an electoral system that is proportional, like any electoral system, may treat the parties symmetrically and thus fairly. ${ }^{37}$ Yet symmetry can

\footnotetext{
36 Davis v. Bandemer, 478 U.S. at 162 (Powell, J., concurring in part and dissenting in part).

${ }^{37}$ Electoral systems that mandate versions of proportional representation do not necessarily produce partisan symmetry. For example, many European nations that use proportional representation have electoral rules that, as applied, generate electoral systems with sometimes considerable partisan bias. This may occur in a multi-party system when very small parties fall below legal thresholds and so get no seats and as a result larger parties gain more than a proportional share of seats.
} 
exist (or not exist) in all types of electoral systems. Because most electoral systems in the United States are single-member districts that are winner-take-all, in practice they normally give a "bonus" of varying sizes (above proportionality) in seats to the party that wins a majority of the votes across a state. So long as this bonus is awarded based on whoever wins the majority, rather than to a specific party by name, it would be fair under the partisan symmetry standard despite giving non-proportional results.

The range of electoral systems that are symmetric can be ordered by the degree of electoral responsiveness. Electoral responsiveness-also referred to as the "bonus" for the majority party, the "swing ratio," or the "degree of representation" - quantifies this idea by asking how much the seat division between the parties change as the vote proportions change. A purely proportional system is one in which a one percent increase in the votes for a party leads to a one percent increase in seats for that party. Statistical models of plurality-based elections have demonstrated that plurality-based elections are only rarely proportional, i.e., they exhibit an electoral responsiveness that is different from one. If, for example, the electoral responsiveness were 2 , and there were only two political parties, this would mean that, on average, for every one percentage point gain in vote share above but near $50 \%$ a party could expect to gain an additional 2 percentage points of seat share in the legislature, e.g., for a vote share of 60 percent, a party could expect to control roughly 70 percent of the seats in the legislature. This common pattern violates proportional representation but does not violate symmetry, so long as whatever party wins a majority of the votes gets the bonus. Under symmetry, there is nothing necessarily unfair about one party winning a greater proportion of seats than the other, so long as that "one party" is not any particular party. An electoral system may have any degree of partisan bias, no matter what level of responsiveness happens to exist.

Electoral responsiveness is often regarded as a normatively good feature of elections. Certainly elections in which the seat division between the parties did not respond at all to changes in voter preferences would not be de- mocratic. Low levels of responsiveness can be produced by a legislative redistricting plan, or by other features of elections, such as high levels of incumbency advantage, many uncontested elections, weak candidates, or a politically polarized electorate. Most scholars therefore regard electoral systems with higher levels of electoral responsiveness as better, ${ }^{38}$ and this is one of the reasons many favor the American system of district-based elections, since it tends to produce a higher level of responsiveness than other systems. A few state constitutions favor what we think is properly conceptualized as high levels of electoral responsiveness, i.e., a preference for competitive seats, but it is not clear that the Supreme Court has addressed this issue other than to explain that in making partisan gerrymandering justiciable, they were not favoring proportional representation. That makes a great deal of sense in this context, because requiring proportional representation in the American context of single member district plurality-based elections is effectively synonymous with requiring low levels of electoral responsiveness, something that few favor and something that has little basis in American law.

\section{Measurement}

The concept of partisan symmetry explicated above is important in and of itself, but even a clear concept that everyone accepts as relevant does not immediately suggest a specific method of measuring that concept, or any rule that would necessarily apply in the legal setting. These two additional goals of measurement and legal application require, first, a statistical measure of the deviation of an electoral system from partisan symmetry; in other words, we need a measure of partisan bias. (For some purposes we describe below, we may also desire a measure of electoral responsiveness, which distinguishes different types of fair electoral systems.) Second, the Court will then also need to determine how to make use of such

\footnotetext{
${ }^{38}$ An exception is Thomas L. Brunell, Rethinking Redistricting: How Drawing Uncompetitive Districts Eliminates Gerrymanders, Enhances Representation, and Improves Attitudes Toward Congress, 39(1) PS: Political Science \& Politics 77-85 (January, 2006).
} 
measures, but that is a separate issue we defer until Section III.

Over the many years in which scholars have worked on defining fairness as partisan symmetry, they have also developed a sequence of steadily improving statistical approaches designed to measure the degree of partisan bias in elections and in proposed legislative redistricting plans. These now highly mature statistical methods rely on well-tested and well-accepted statistical procedures.

Estimating partisan bias and electoral responsiveness both first require studying how the statewide average district vote for Democratic candidates (which in our simple two-party running example is $100 \%$ minus the fraction for the Republican candidates) will translate into the expected statewide fraction of seats for the Democratic Party. The relationship between these two variables is typically summarized with the seats-votes curve, which traces out the expected statewide seats division as a function of each possible value of the average district vote (i.e., for each average district vote percent for the Democrats between $0 \%$ and $100 \%$, or at least near the middle of that scale where real results occur more commonly). Once we have traced out the seats-votes curve, we can compute partisan bias by directly examining how each party would fare in obtaining seats for any given vote fraction. For example, we could literally read off the expected seat proportion the Democrats would likely receive if they won $55 \%$ of the vote in the average of the districts in the state, and the seat proportion for the Republicans if they received $55 \%$ of the vote. Similarly, the seats-votes curve also reveals the level of electoral responsiveness by the slope of the line near the middle of the curve where most elections take place: steeper slopes mean that a small change in the average district vote (for either party) would yield a larger change in the seat division between the parties than if the seats-votes curve were flatter. It is important not to confuse electoral responsiveness, which refers to the slope of seats-votes curves and helps to distinguish different types of fair systems, with partisan bias, which refers to the degree to which an electoral system deviates from partisan symmetry. The two are totally distinct concepts.

Because we can measure both partisan bias and electoral responsiveness directly from the seats-votes curve, all that remains is to (a) identify a method of estimating the seats-votes curve from the data we observe, and (b) specify a statistical methodology that allows us to estimate the margin of error that exists in the measurements we derive from the seats-vote curve.

Historically, four general categories of methods have been used to measure seats-votes curves, each one better than the previous. ${ }^{39}$ To offer intuition about how one can estimate the relationship from real data, and also to give a sense of the real scientific progress made in this field, we now briefly describe each approach.

The first method developed to measure a seats-votes curve was to take a number of election results and to plot the actual statewide average district vote by the statewide seat proportions, with one point representing each election. The strategy is then to fit some type of linear or nonlinear regression to these points and use that estimated regression line as the seats-votes curve. (The margin of error in the seats-votes curve measured this way is estimated from how closely the points fit the curve.) This approach works fine in principle, except that there are usually five or fewer elections between redistrictings, which is too few to pin down the seats-votes curve with much certainty. More importantly, this approach cannot be applied directly to evaluate redistricting plans before they are put into effect or even before the next redistricting is about to take place, and so it is useful only for historical and comparative purposes. ${ }^{40}$

A second strategy for measuring the seatsvotes curve is to use a key relationship evident in the vast majority of district election data to construct the hypothetical relationships be-

\footnotetext{
${ }^{39}$ Andrew Gelman and Gary King, Estimating the Electoral Consequences of Legislative Redistricting, 85(410) Journal of the American Statistical Association 276 (June 1990). ${ }^{40}$ See M.G. Kendall and A. Stuart, The Law of Cubic Proportions in Electoral Results, 1 British Journal of Sociology 193-196; James G. March, Party Legislative Representation as a Function of Election Results, 21(4) Public Opinion Quarterly 512-542 (Winter 1957-58); Phillip A Schrodt, A Statistical Study of the Cube Law in Five Electoral Systems, 7 Political Methodology, 31-53; Bernard Grofman, Measures of Bias and Proportionality in Seats-Votes Relationships, 9 Political Methodology 295, 327 (1983); Richard G. Niemi and Patrick Fett, The Swing Ratio: An Explanation and an Assessment, XI,1 Legislative Studies Quarterly 7590 (February, 1986); Gary King and Robert X. Browning, Democratic Representation and Partisan Bias in Congressional Elections, 81 Am. Pol. Sci. Rev. 1251 (1987).
} 
tween votes and seats from the district-level votes in only one election. The idea is to plot first the one point representing the observed proportion of seats and of votes in the one actual election. Then one assumes that, if the swing in votes for the Democratic Party statewide increased by (say) one percentage point, the same uniform swing would occur in every district within the state. We can use this "uniform partisan swing" assumption by adding one percentage point to each district in the state and then declaring the candidates "winners" in each district based on these new hypothetical vote results; this produces one additional point on the seats-votes plot. The same procedure is repeated by adding (and subtracting) a large range of values uniformly one at a time to all districts and recomputing the statewide seat totals. In this way, we can reconstruct an entire seats-votes curve based on this one assumption. ${ }^{41}$

This uniform partisan swing strategy is an improvement since by marshaling district-level data, it productively uses much more information than the first cross-election approach, and yet it requires only a single actual election. Unfortunately, the approach still has three serious flaws for use in evaluating redistricting. First, it does require this one election, and so we could not evaluate the consequences of redistricting plans with this approach until after the first election held under the new plan. Second, although it is remarkable that the uniform partisan swing assumption does hold approximately in a vast array of democratic elections in the U.S., worldwide, and throughout history, ${ }^{42}$ the assumption (which requires uniform swing to hold exactly) is violated to a degree by almost all actual election data. And finally, the assumption of exact uniform partisan swing implies a zero margin of error in terms of predictive accuracy, which is always unrealistic in social science analyses. Newer methods address one or all of these three disadvantages.

The third approach to estimating the seatsvotes curve eliminates the need to wait until after the first election. The idea is to create hypothetical votes in districts under the new redistricting plan by using the actual votes cast in a previous election for some statewide race (often a low visibility race, such as state treasurer or board of regents) and breaking them down into the new districts. ${ }^{43}$ The assumption here is not that the votes in the statewide race are the same as those that would be received by the legislative candidate in the district election, but rather only that the relationship between votes and seats can be estimated in this way. This assumption corresponds to the idea that, if you ranked the degree to which districts were Republican based on legislative elections or elections to a statewide office, the rank order, and not necessarily the actual vote, would be approximately the same. This assumption is often accurate, but never exactly of course. For example, the incumbency status of the legislators, and their typical electoral advantage, is ignored, as are many other important political differences in each legislative district election. The lack of a realistic (nonzero) margin of error is also not fixed by this approach. Thus, even though this method sometimes provides a reasonable measure of the seats-votes curve, and in turn the degree and direction of partisan bias and the extent of electoral responsiveness, this method can be improved on.

The fourth and current state of the art approach, developed in a sequence of articles by Gary King and Andrew Gelman, ${ }^{44}$ builds on

41 David E. Butler, Appendix, The British General Election of 1950, H. G. Nicholas, Ed., pp. 305-333 (London: Macmillan, 1951).

42 See Gary King; Ori Rosen; Martin Tanner; and Alexander F. Wagner, Ordinary Voting Behavior in the Extraordinary Election of Adolf Hitler, <http://gking.harvard.edu/ files/abs/naziV-abs.shtml>, which offers examples of uniform partisan swing in the U.S. Congress, the Oklahoma State House, the Weimar Republic, and the Parliament of the Russian Federation.

${ }^{43}$ See C. Backstrom, L. Robins, and S. Eller, Issues in Gerrymandering: An Exploratory Measure of Partisan Gerrymandering Applied to Minnesota, 62 Minnesota Law Review 1121-1159 (1978).

44 This approach was built over four successive articles, each which improved on the previous: Gary King, Representation Through Legislative Redistricting: A Stochastic Model, 33(4) Am. J. Pol. Sci. 787-824 (November, 1989); Andrew Gelman and Gary King, Estimating the Electoral Consequences of Legislative Redistricting, 85(410) Journal of the American Statistical Association 274-282 (June, 1990); Gary King and Andrew Gelman, Systemic Consequences of Incumbency Advantage in U.S. House Elections, 35(1) Am. J. Pol. Sci. 110-138 (February, 1991); and Andrew Gelman and Gary King, A Unified Method of Evaluating Electoral Systems and Redistricting Plans, 38(2) Am. J. Pol. Sci. 514-554 (May, 1994). The method in the latter article is implemented in the open source and free software called "JudgeIt: A Program for Evaluating Electoral Systems and Redistricting Plans," by Andrew Gelman and Gary King $<$ http://gking.harvard.edu/stats.shtml\#judgeit $>$. 
the insights of the above earlier methods in three key ways. First, instead of assuming that uniform partisan swing holds exactly, it only requires the statistical assumption of approximate uniform partisan swing. This more realistic assumption has been shown to fit electoral data very closely in a vast array of elections, and so is appropriate to evaluate almost all American legislative electoral systems. In fact, the same pattern holds for elections of all kinds in the U.S., and even elections in other countries. For example, we may not have any idea how the next presidential elections will turn out but, whatever the exact results for elections in this decade, we know with a high degree of certainty that the overall vote in Utah will be more Republican than that in Massachusetts. In Republican years, both will typically become more Republican, and in Democratic years they will both usually become more Democratic but, whatever the nationwide swing, the ordering of and distance between the two will remain roughly the same.

This insight is a key empirical generalization that applies to all elections in the U.S. and most other democracies: the statewide or nationwide swing in elections is highly variable and difficult to predict, but the approximate rank order of districts is highly regular and stable. The rank order is not perfectly fixed, and local political changes can and regularly do affect them, but this uncertainty is reflected in the statistical assumption of approximate uniform partisan swing, and the changes in the ranking of different areas is usually relatively small and within predictable margins of error. ${ }^{45}$ Fortunately, the methodology necessary to estimate partisan bias requires no predictions about the swing, and indeed is not affected by whether it is a Democratic or Republican year or whether one will be more prevalent than the other. It is instead based only on this regular feature of elections that helps establish the relationship between any particular vote outcome and the likely resulting seat division.

The second advantage of this new approach is that it does not require assuming that votes in statewide elections for statewide candidates have any particular ex ante relationship with votes for legislative candidates. Instead, this methodology has adapted, incorporated, and extended standard statistical approaches (based on linear regression, one of the most commonly used methodologies in the social sciences) to measure what seat outcomes would be like given particular average district vote proportions by estimating outcomes from the available historical data. Estimating whether such a relationship exists, and what it is, is a strategy in stark contrast to previous methods, which had merely assumed that the vote for a statewide office would be a perfect predictor of results in legislative districts. In fact, the new method allows the use of any available information about the determinants of partisan voting strength in the new districts, including recent election results, the presence of an incumbent in the district, and whether the race is contested. Other factors may include party registration data, prior party control of the district, incumbency status, candidate quality, or demographic characteristics of the voting age population.

The first three approaches to estimating seats-votes curves also have the disadvantage of being sensitive to the choice of election data used and other inputs to the calculations, because, for example, you must choose which statewide office to use for the elections under study. These methods will sometimes produce very different estimates of partisan bias with a different choice of statewide office. The state of the art fourth approach does not have this disadvantage, because all available data may be used, we do not need to assume that people vote the same way for statewide offices as in legislative elections, actual election data from the legislature under study are used, and special statistical procedures are introduced that make the method work even when highly predictive variables are not available. Implemented properly, estimates of partisan bias for a particular redistricting plan tend to be quite similar, and within the margin of error, even if

${ }^{45}$ A partial exception is when we have a massive realignment under way, but in many such situations, it is usually the case that, within any given state, electoral tides are moving generally in the same direction and so the assumption still holds. 
available explanatory variables change to a large degree. ${ }^{46}$

The final advantage of the new approach is that allowing approximate uniform partisan swing also turns out to provide accurate statistical measures of the "margin of error," so that we can know how confident we can be in the values we get for partisan bias. In this way, courts can be aided in determining the weight to give an expert's testimony about the magnitude of partisan bias.

In its present form, this standard methodology for measuring symmetry and partisan bias is well-established, widely accepted, peer-reviewed, and highly reliable.

\section{Prospective versus retrospective tests}

The durability of partisan gerrymandering effects. The approach to partisan gerrymandering based on symmetry allows us to deal not only with the issue of severity in the form of the magnitude of partisan bias, but also with the issue of the expected durability of partisan gerrymandering effects that was raised by the Bandemer plurality. ${ }^{47}$ The Bandemer Court required that gerrymandering be durable in its effects before it could rise to the level of a constitutional violation (the redistricting must "consistently degrade" a voter's or group of voters' influence on the political process as a whole). In effect, under that standard, plaintiffs must show that they have little or no hope of overcoming the plan's discriminatory bias.

It is sometimes claimed that we do not need to worry about a redistricting's partisan impacts because these will "wear off" over the course of a decade. In general, that need not be true. It is certainly true, of course, that those attempting gerrymandering do not always achieve the effects they intend. And, if they make a mistake gerrymandering, the partisan effects of their efforts can wear off over time, or even be reversed. ${ }^{48}$ But that gerrymandering does not always work, or even that it sometimes fails over time, certainly does not mean that there can be no such thing as a successful partisan gerrymander. The methodology we propose allows us to distinguish those cases in which a gerrymandering might have been attempted but was not very well done from those cases in which the partisan bias imposed by gerrymandering is expected to be both substantial and long-lasting. While measures of partisan bias involve "if, then" scenarios rather than crystal ball gazing, there are special circumstances in which it may be possible to anticipate durable partisan biases that lock-in particular outcomes or ranges of outcomes.

Journalistic accounts of partisan gerrymandering often describe it as a process of packing one's opponents into as few districts as possible and seeking to win the remaining districts by the barest of margins. While there is a good deal of truth in this portrait, more sophisticated analyses have shown it to be flawed. "Efficient" partisan gerrymandering is forward looking, and seeks to take into account the magnitude of longer run "electoral tides." 49 Thus, skilled gerrymanderers draw districts for the party intended to be the beneficiary of the gerrymander with expected margins that are large enough to insulate those districts from expected changes over times in voter preferences.

${ }^{46}$ In any challenge to a plan as an unconstitutional partisan gerrymander courts will apply the traditional criteria for admitting expert evidence and determine in each case (1) whether the experts are qualified; and (2) whether their particular analyses are reliable. Indeed, as noted earlier, courts regularly use statistics in a number of different areas of voting rights law. For example, statistical measures are commonly used to determine levels of racial bloc voting and to help decide whether a minority group can elect a candidate of its choice (see Thornburg $v$. Gingles, 478 U.S. 30, 52-53 (1986)). In each instance, the court must make a judgment about the expert and the methodology. For a thorough discussion of the different statistical standards used to determine whether a plaintiff has met the Gingles test and their reliability, see Bone Shirt v. Hazeltine, $336 \mathrm{~F}$. Supp. 2d 976, 995-1005 (D.S.D. 2004) (discussing the various standards and surveying cases that apply these standards).

${ }^{47}$ Davis v. Bandemer, 478 U.S. 109 (1986).

${ }^{48}$ Indeed, failure to take into account anticipatable changes over time in voter support (i.e., failing to read the "handwriting on the wall") can convert a plan that was intended to have been gerrymandered to favor Party A into a plan whose actual consequences are to favor party B. See Bernard Grofman and Tom Brunell, "The Art of the Dummymander: The Impact of Recent Redistrictings on the Partisan Makeup of Southern House Seats," in Peter Galderisi (Ed.), Redistricting in the New Millennium pp. 183-199 (Lexington Press, 2005).

${ }^{49}$ For a discussion of efficient partisan gerrymandering see Guillermo Owen and Bernard N. Grofman, Optimal partisan gerrymandering, 7(1) Political Geography Quarterly 5-22 (1988). 
That is, they attempt to draw districts so as to result in high levels of partisan bias in their favor and low levels of electoral responsiveness.

When we have skillful partisan gerrymandering, we see low levels of electoral responsiveness being implemented by the party doing the gerrymandering protecting incumbents of its own party with safe seats, and packing partisans of the opposing party into seats that can be confidently expected to be very safe for the minority party candidate in the district over the course of a redistricting decade. Thus, when we have sufficiently skillful partisan gerrymandering, rather than the constituents choosing their legislator, those drawing the lines choose each legislator's constituents in such a fashion that the non-term-limited legislator can expect to be safe as long as the legislator chooses to run for reelection, unless there is a truly enormous voter swing. ${ }^{50}$ Indeed, if they are given a district free of competition from a fellow legislator of their own party, sometimes self-interested incumbent legislators of the minority party are very happy with the results of a partisan gerrymander for the other party because their own seats have been made so safe. ${ }^{51}$ But party leaders of the minority party, especially those from outside the legislature, are likely to be left very unhappy because the way in which lines have been drawn essentially freezes in the minority party's status as a minority party. Fortunately, the same concepts of bias and responsiveness, and the methodology used to measure them that we have described, can be used to assess both the bias of a plan and the expected durability of its effects.

Hypothetical, versus directly observed, unequal treatment. Justice Kennedy makes it clear in his opinion that he is bothered by the fact that estimates of partisan bias commonly rely on projecting previous information from previous elections into the future: "Even assuming a court could choose reliably among different models of shifting voter preferences, we are wary of adopting a constitutional standard that invalidates a map based on unfair results that would occur in a hypothetical state of affairs." ${ }^{2}$ Consequently, as noted earlier, his opinion suggests that litigation might be better delayed until levels of partisan bias could be observed directly from one or more elections under a given plan. We do not wish to discourage partisan gerrymandering law suits being brought after an election had taken place under a new plan, since then any harm from the redistricting plan can in fact be judged with somewhat less uncertainty after the election. Moreover, if the Court required partisan symmetry to be part of the judicial standard of partisan gerrymandering only after the first election, redistricters would surely anticipate this in drawing the districts in the first place, especially since it is so easy to assess the plan before the election. Nevertheless, there exist a number of reasons to think that the plurality language in Bandemer ${ }^{53}$ allowing for reliance on either an "actual" or a "projected" history of disproportionate results is to be preferred to an insistence that only evidence from elections conducted under a plan be regarded as probative. We outline those reasons here.

First, as noted above, use of a partisan symmetry test does not involve predicting actual election outcomes in the form of vote shares. The redistricting plan itself, which is the document that to be declared constitutional or not, exists prior to the election and observing it involves no hypotheticals or counterfactuals. Moreover, the effect of the redistricting plan can be directly estimated before the election based on conditional, statistically grounded assertions about what would happen to outcomes if any particular aggregate vote share percent-

50 The minority party members are given really safe seats with the intention of concentrating the votes of their party's supporters in as few seats as possible; but the members of the majority party are also given safe seats, now with the intention of making sure that those seats remain safe over the course of subsequent elections.

51 As noted in the plurality opinion in Vieth at 571-2, "efforts to maximize partisan representation statewide might well begin with packing voters of the opposing party into the districts of existing incumbents of that party. By this means an incumbent is protected, a potential adversary to the districting mollified, and votes of the opposing party are diluted."

52 LULAC, 126 S. Ct. at 2611 (opn. of Kennedy, J.). Justice Breyer in Vieth refers to situations where a majority party in votes has twice been denied a majority of seats as evidence which might compensate for the absence of other indicia of unjustified entrenchment of a minority party in power.

${ }^{53}$ Davis v. Bandemer, 478 U.S. 109, 140 (1986). 
age were achieved by a given political party's candidates. Measurements by experts about partisan bias in a redistricting plan are thus not efforts to divine the future. For example, in a single district election, the claim that "electoral rules declare whichever candidate who garners a plurality of the vote the winner of the seat" is an example of an if-then statement, and requires no prediction about or knowledge of which party will win the vote plurality. Similarly, the statements required in ascertaining partisan bias are statements about what level of asymmetry can be expected in translating the votes for the Democratic and Republican candidates in a legislature into seats in that legislature if, in the future, there were to exist a particular level of voter support for each party. The level of support that voters give to the parties is the voter's own business and is not stipulated ex ante as part of this definition of fairness. Rather, by examining all the relevant data and the potential seat divisions that would occur for particular vote divisions, social scientists can compare the potential scenarios and determine the consequences for partisan bias of a map, separating out other potentially confounding factors. The question is not whether a particular party will win; it is whether the redistricting plan on the table has stacked the deck to such a degree that the plan burdens the other party's "rights of fair and effective representation." ${ }^{\prime \prime}$

Second, as also noted above, the assumptions used are relatively weak ones, involving only relative propensities of the voters within a particular geographic area in a state to vote for a given political party as compared to voters within some other geographic area. It is an empirical question as to whether units of geography can be distinguished in their partisan propensities, and thus whether partisan gerrymandering is even possible. But if partisan gerrymandering is possible, then systematic measurement of it is possible. Just as racially polarized voting is a "linchpin" of racial vote dilution claims, even though vote dilution and racial polarization are completely distinct concepts, so the empirical claim that partisan propensities exist in a jurisdiction that are strong enough to allow us to roughly rank order units of geography in their expected parti- sanship is a necessary predicate of any partisan gerrymandering claim. ${ }^{55}$

Third, when we look at actual evidence about the predictive power of this methodology we are reassured about its usefulness. For example, in expert witness testimony in a California congressional districting case of the 1990s by Bernard Grofman, specific claims were made in 1994 about a "Democratic lock" that would be expected to last the rest of the decade barring substantial changes in California statewide voting patterns. These observations turned out to be highly accurate. ${ }^{56}$ Similarly, predictions given in expert witness testimony in Federal District Court by Gary King for every district election in the Ohio State House and Senate also proved highly accurate. ${ }^{57}$

Fourth, the use of this methodology by the experts for opposing sides who testified about partisan gerrymandering in the cases consolidated into LULAC (Professor Alford and Professor Gaddie) were in remarkable agreement about the partisan implications of the plans whose partisan bias they investigated. As Justice Stevens points out: "According to Professor Gaddie, the State's expert, Plan 1374C gives Republicans an advantage in 22 of 32 congressional seats. The plaintiffs' expert ... agreed. [That expert] added that in his view, the only surprise from the 2004 elections was 'how far things moved' toward achieving a

${ }^{54}$ Vieth, 541 U.S. at 312 (Kennedy, J., concurring in the judgment).

${ }^{55} \mathrm{~A}$ variant of this point is made by Justice Souter (joined by Justice Ginsburg) in their dissenting opinion in Vieth, at 602 , who argue that, to bring a successful partisan gerrymandering claim, it must be shown that plaintiffs are a member of a politically "cohesive" group. However, we would emphasize that the test we propose, based on behavior at the level of units of geography, is less restrictive than that suggested by Justices Souter and Ginsburg, since our test refers only to the potential for partisan gerrymandering based on geographically-based districts, and does not require analysis at the individual voter level. 56 See Bernard Grofman, Declarations in Badham v. Eu (excerpts), PS 544-549, 573-574 (Summer 1985); cf. Bernard Grofman, Introduction to Minisymposium on Political gerrymandering: Badham v. Eu, Political science Goes to Court, PS 538-543 (Summer 1985).

57 These predictions were reported in Andrew Gelman and Gary King, A Unified Method of Evaluating Electoral Systems and Redistricting Plans, 38(2) Am. J. Pol. Sci. 514-554 (May, 1994). 
22-10 pro-Republican split 'in a single election year.' " 58

While such congruence among experts for opposing sides cannot prove that the methodology for determining partisan symmetry is valid for predictive purposes, it enhances our confidence that courts can find credible expert witness testimony to give reliable estimates that can be helpful in resolving partisan gerrymandering cases. The assertions that using assessments of hypotheticals based on previous election results (and some statistical calculations) to calculate levels of partisan bias is beyond the competence of expert witness testimony, or results in claims whose credibility cannot be evaluated by courts, is simply wrong. In cases involving racial vote dilution claims under the $14^{\text {th }}$ Amendment or under Section 2 of the Voting Rights Act of 1965 as amended in 1982, for almost forty years, expert witnesses have been routinely making use of hypotheticals in a very similar way to what would be required in calculations of partisan bias. What experts in these racial cases have done is use previous election outcomes and knowledge of racial demography to calculate the hypothetical minority population proportion needed to provide minorities a realistic opportunity to elect candidates of choice with votes entirely from within the minority group, and/or the hypothetical minority population proportion needed to provide minorities a realistic opportunity to elect candidates of choice if there is a given level of reliable white crossover voting.

Fifth, in voting rights cases, courts commonly make what we might think of as "presumptive" findings of statutory or constitutional violations. For example, in looking at plans under the Voting Rights Act, it is almost inevitable that a plan will be evaluated for Section 5 compliance before any elections have been held under the plan. There is no obvious reason why an analogous rule should not apply to partisan gerrymandering.

Finally, and relatedly, there are also good reasons to think that a gerrymandering standard that is addressed to prospective harms rather than to harms already committed can be lawful. Consider, for example, a claim that a contractor has violated fiduciary obligations or been guilty of wrongful neglect by using a ce- ment mix that is likely to crumble over time. We would not want to have to wait until the building collapsed to compel a remedy. Nor would we need to know exactly when the disaster was going to occur as long as its occurrence could be reliably predicted. Moreover, in the context of redistricting, once lines have been redrawn to favor a given party, the electoral advantage of incumbency will be conferred on the winners, who will then carry this advantage into new elections, which may make it harder to undo the damage from an illegal partisan gerrymander than if the problem were avoided in the first place. In addition, the minority party "will surely have a more difficult time recruiting strong candidates, and mobilizing voters and resources, in these ... safe districts." 59

\section{Avoiding common misunderstandings}

We conclude this section by discussing and clarifying ten misunderstandings about symmetry and partisan bias that should be avoided. We have drawn our illustrations of these misunderstandings primarily from the briefs of various of the Appellees and amici in Jackson $v$. Perry, one of the cases consolidated under the name LULAC $v$. Perry. We believe the discussion below can be helpful to courts reviewing expert witness testimony and legal arguments about the nature of partisan bias and partisan fairness.

First, it is sometimes claimed, as in the Brief of Appellees Tina Benkiser, Chairman, Republican Party of Texas, and John DeNoyelles in Jackson v. Perry, ${ }^{60}$ that the methods described above cannot be applied because results will be so dependent upon which particular elections and other data are used that no meaningful calculations about the magnitude of partisan bias

\footnotetext{
${ }^{58}$ LULAC, 126 S. Ct. at 2626-2637 (n. 6) App. to Juris Statement at 225a (declaration of John R. Alford, Ph.D.). Justice Stevens (n. 7 at p. 20) notes that Republicans won " 21 of the 22 seats that had been designed to favor Republicans in Plan 1374C," and goes on to comment that the evidence suggests that the lone exception, Representative Edwards, who won by only $51 \%$ of the vote, may not be safe in 2006.

${ }^{59}$ LULAC, 126 S. Ct. at 2640 (opn. of Stevens, J.).

${ }^{60}$ At pp. $18-19$, n.10.
} 
can be provided. Given modern technology, that claim is false. Experts can disagree about which set of input data is relevant for a given case, but the resulting measures of partisan bias normally will not differ to any significant degree because the best current methods are quite robust to changes in model specification. Because social scientists studying partisan bias rely on the symmetry standard as the baseline for attempting to calculate the degree of bias, differences of opinion between experts will be limited in scope. In practice, differences across experts in the academic literature, and even those on opposite sides in redistricting litigation have usually been minor, especially when considering the margin of error properly calculated. We expect that the methodology of ascertaining the seats-votes curve from real data, and then measuring partisan bias (and electoral responsiveness, if desired) will continue to improve, but the current state-of-the art methodology has now matured to the point where the vast majority of the available relevant information is now incorporated in the methods, and so future improvements will likely be incremental, such as helping to handle special cases or unusual situations.

Second, some make the claim that the symmetry standard is yet another version of a proportionality rule. ${ }^{61}$ This assertion is factually incorrect. ${ }^{62}$ Those making such a claim are conflating two very different concepts, proportionality and symmetry, by confusing electoral responsiveness with partisan bias. Perfect proportionality is allowed as one possible fair system under the symmetry definition of fairness, but symmetry does not require proportionality. Fairness in the form of symmetry can exist in electoral systems that are far from proportional. In particular we can have the absence of partisan bias (or its presence at only very low levels) in systems such as plurality elections in the U.S. that have electoral responsiveness values that are very far from one. On the other hand, limiting the level of partisan bias in a system has no necessary effect on the system's level of electoral responsiveness, and thus will have no necessary effect on the degree to which a system is proportional.

Third, not all methods of analyzing seatsvotes curve are equally useful to the courts. As demonstrated in the discussion of the evolution of the social science literature on this subject, the statistical technology to investigate seatsvotes relationships has now matured to the point where it can be counted on to provide reliable information for public policymakers, the courts, and others involved in redistricting. However, when laypersons are discussing data on seats-votes curves they sometimes present and analyze that data in a misleading way. For example, in the State Appellees Brief in Jackson v. Perry, and in the Republican Party of Texas Brief in Jackson v. Perry, data are reported on statewide vote shares and on statewide seat outcomes and the two numbers are compared to provide an indicator of partisan fairness. ${ }^{63}$ But, this simplistic mode of analysis makes it virtually impossible to distinguish discrepancies between seat share and vote share that are caused simply by levels of electoral responsiveness higher than one from discrepancies that are caused by actual partisan bias.

${ }^{61}$ See e.g., State Appellees Brief in Jackson v. Perry, at p. 46.

${ }^{62}$ In the plurality opinion in Vieth authored by Justice Scalia, the Court reiterates its long standing view that "the Constitution provides no right to proportional representation." This is a legal conclusion, and so not in our purview, but in any case, not one with which we would disagree. Indeed, we would note that the use of plurality elections in single seat and multi-seat districts (and in atlarge elections) at the time of the founding reinforces the view that the Constitution has no mandate for proportional representation in either method or result, and the continued use of plurality-based elections after the passage of the Civil War Amendments further reinforces this conclusion. However, the plurality opinion in Vieth, also asserts that the claim that a map is unconstitutional because it "can thwart the plaintiffs' ability to translate a majority of votes into a majority of seats" is equivalent to requiring proportional representation. That is a statement about political science methodology, and one that is erroneous. Nonetheless, we should also be equally clear that in this article we are not asserting that any plan that thwarts a party's ability to translate a majority of votes into a majority of seats must necessarily be held unconstitutional. Rather, we are simply proposing a way to measure the magnitude of partisan bias, and leaving it entirely up to the Supreme Court to determine the magnitude of (durable) partisan bias that rises to the level of a (prima facie) constitutional violation. See extended discussion of the issue of thresholds and manageable standards in Section IV.

63 Brief of Appellees Tina Benkiser, Chairman, Republican Party of Texas, and John DeNoyelles in Jackson $v$. Perry, at pp. 21-26). 
A fourth empirical misunderstanding is found in the statement in the plurality opinion in Vieth, that, "even if a majority party could be identified, it would be impossible to assure that it won a majority of seats unless the States' traditional election structures were radically revised." ${ }^{64}$ This point is linked to an important insight into a statistical feature of plurality elections discussed above, namely that pluralitybased elections cannot be expected to generate proportional outcomes because of what is sometimes referred to as the "bonus effect," and hence it is inappropriate to use proportionality in the outcomes of plurality-based elections as a test for partisan fairness or of the equality of treatment of the voters who are the supporters of the (two) parties. But, as we emphasized earlier, from the fact that we cannot expect plurality-based plans to be proportional, it does not follow that we cannot apply the quite different concept of partisan bias to evaluate plans that use plurality based elections (see further discussion of crafting of judicially manageable standards in Section IV below). In fact, since partisan symmetry does not imply proportionality, the problem identified is not a problem.

A fifth misunderstanding is found in the plurality opinion in Vieth that begins with the fundamentally sound insight into real world politics that "a person's politics is rarely as readily discernible-and never as permanently discernible - as a person's race. Political affiliation is not an immutable characteristic, but may shift from one election to the next; and even within a given election, not all voters follow the party line. We dare say (and hope) that the political party which puts forward an utterly incompetent candidate will lose even in its registration stronghold." ${ }^{65}$ Considerable literature in political science supports this claim of the four Justices in the Vieth plurality that voter choices may vary from election to another, and that there are idiosyncratic reasons why one candidate of a party may do well and another do badly. But they go too far when they also claim that these facts make "it impossible to assess the effects of partisan gerrymandering, to fashion a standard for evaluating a violation, and finally to craft a remedy." 66

That claim does not follow from the empiri- cal regularity noted, four sub-points about which are critical.

$A$. As noted earlier, the empirical findings necessary for experts to demonstrate partisan gerrymandering are directed at characteristics of the electoral system, and thus based on "if, then" scenarios, not on predictions about vote shares.

$B$. The second point has to do with drawing the correct implications of the fact that partisan propensities are not fixed, immutable features of human beings. Far from this being a problem for using the methodology used to calculate partisan bias, it is precisely this mutability that allows us to make use of the standard social science methodology necessary for measuring partisan bias. ${ }^{67}$

C. Regarding the mutability of partisanship, the partisan bias methodology we propose is makes only a very weak assumption, namely that different units of geography can be approximately rank ordered in terms of their average partisan propensities.

$D$. Finally, because measuring deviations from symmetry requires understanding hypothetical scenarios about the consequences of changes in partisan vote shares, in order for partisan bias calculations based on such scenarios to be meaningful, these changes in vote shares must, at least in principle, be feasible ones. ${ }^{68}$ For example, consider a state where the Democrats consistently receive $80 \%$ of the average district vote in election after election, decade after decade, and where we therefore have no experience of the Republicans ever coming close even remotely to a majority, much less $80 \%$. In this situation, even though the concept of partisan symmetry still applies in theory, ascertaining what would happen to the seat division in symmetric situations where

${ }^{64}$ Vieth, 541 U.S. 267 at 552.

65 Vieth, 541 U.S. 267 at 286 (internal citations omitted).

66 Vieth, 541 U.S. 267 at 287.

67 Put differently, a partisan symmetry test for the magnitude of partisan bias is easy to apply in normal, healthy, democratic electoral systems. That is because in such systems, not everyone always votes consistently for the same party.

${ }^{68}$ Similarly, as we discuss in Section $\mathrm{V}$, applying the symmetry methodology to evaluate the equality of treatment for groups with fixed characteristics, such as race, is not sensible. 
each party in turn received some fixed percentage of the vote would be so far from the historical experience that no empirical method could be reliably used to ascertain the degree of partisan bias. ${ }^{69}$ Thus, the methodology we propose is intended only for jurisdictions where the politics is competitive enough that it is empirically feasible to develop reliable expectations what each party would receive in seats if it won a given sized majority of the votes. ${ }^{70}$ Because we are not proposing to apply this methodology in every situation, but only in potentially competitive jurisdictions, where the consequences of gerrymandering might be especially onerous in thwarting the will of the majority, the burden on courts of seeking to apply our methodology is correspondingly limited. ${ }^{71}$ Which settings are appropriate (in a statistical sense) for application of the methodology used to establish partisan fairness is appropriately a topic for expert witness testimony, but in most jurisdictions which go to litigation this issue is likely to prove completely unproblematic.

A sixth and related error about the partisan bias approach has to do with claims that it requires us to consider empirically implausible as well as purely hypothetical outcomes. State Appellees in their Brief ${ }^{72}$ claim that the symmetry standard is "designed to address only the rare if not unprecedented situation of an electorate shifting near instantaneously from a majority (of $58 \%$ or more) of one party to a comparable majority of another." Of course, this clever phrasing is a complete mischaracterization of how deviations from partisan symmetry are established. The symmetry definition does not, in any way, envision instantaneous shifts of huge magnitude. Rather, it considers possible outcomes in the range where elections are reasonably competitive (such as from $40 \%$ to $60 \%$ for a party). Moreover, as emphasized earlier, we only propose to apply the methodology to jurisdictions where it is factually reasonable to assume that elections can be competitive somewhere within this range.

A seventh and related mistake was made where they claim that "[b]y definition, [the symmetry standard] does not assess the electoral results that will actually be produced by a plan, but makes its validity turn on theoreti- cal results that might occur if political circumstances significantly change." 73 As we have emphasized, there is no way to determine the "electoral results that will actually be produced by a plan" without knowing how voters actually voted. Even when there has been an election under a plan, court determination about that redistricting plan still involves case facts that turn on hypotheticals about how the plan will operate in future elections.

The key assumption behind using hypotheticals in calculating partisan bias is simply that it is possible to approximately rank order units of geography in terms of their partisan propensities. ${ }^{74}$ But, that is exactly what gerrymanderers must do when they decide how to construct their gerrymanders. When we use the methodology described above to calculate partisan bias we are merely positing that it is realistically

69 The problem of counterfactuals (or hypotheticals) posed so far from the data that measurement is difficult or impossible is an important general issue in statistical analysis. See for example Gary King and Langche Zeng, The Dangers of Extreme Counterfactuals, 14(2) Political Analysis (2006); Gary King and Langche Zeng, When Can History be Our Guide? The Pitfalls of Counterfactual Inference, International Studies Quarterly (2006, forthcoming).

${ }^{70}$ Applying the symmetry standard to a political system with consistent one-party control is not feasible or relevant. In electoral systems that do not function as democracies, or have some non- or semi-democratic features such as de jure or de facto one-party rule, or the total absence of partisan competition, other features of the electoral system would need to be studied (or remedied) before it would be reasonable to assess the degree and direction of partisan bias.

${ }^{71}$ However, one qualification is necessary. For state redistricting of Congressional elections, since Congress could be nationally competitive while locally uncompetitive, or nationally uncompetitive while locally competitive, in these situations, we would propose to apply the methodology where either consideration was applicable. However, we recognize that the choice as to how to delimit the domain of cases to which the partisan bias methodology would be applied is ultimately a legal issue even though some restrictions (e.g., to settings that are potentially competitive) are necessary for purely statistical reasons.

72 In Jackson v. Perry, at p. 47.

${ }^{73}$ In the Brief of Appellees Tina Benkiser, Chairman, Republican Party of Texas, and John DeNoyelles (at p. 18).

${ }^{74}$ As suggested earlier, courts often rely on expert witness testimony to do just that. For example, in Balderas $v$. Texas, 536 U.S. 919 (2002), the district court used the number of districts leaning in favor of each party based on prior election results to estimate which congressional districts could be expected to lean toward each party. 
possible to construct a partisan gerrymander by putting together different units of geography. ${ }^{75}$

An eighth error is found in the State Appellees claim ${ }^{76}$ that the symmetry standard does not "account for the heterogeneous distribution of population and political preference." This assertion is false. The symmetry definition of fairness applies directly and straightforwardly no matter how heterogeneous are the voter populations or their partisan preferences. Moreover, the methods that have been developed to measure partisan bias explicitly take into account heterogeneity in district votes, and cause no difficulties for either conceptualization or measurement.

A ninth point of confusion is found in the complaint of the State Appellees" that "no standard exists in the [social science] literature as to how much partisan bias is unconstitutional." While we have no quarrel with that assertion, this brief is obviously confusing issues that are properly in the domain of the courts with those that fall within the expertise of political scientists and other social scientists. Consensus among political scientists about issues in constitutional law is not of legal relevance, ${ }^{78}$ consensus among political scientists about issues of conceptualization and measurement of partisan bias would, on the other hand, be highly relevant were courts to adopt a test that makes use of information about levels of partisan bias, because the fact of such a consensus informs the Court about the likelihood that reliable empirical evidence can be introduced into the record by competent experts about the magnitude of partisan gerrymandering effects.

Similarly, the fact that there is no consensus among political scientists as to what level of partisan bias is unconstitutional does not, as the State Appellees claim," "merely restate the fundamental quandaries that left the Court in Vieth searching for a substantive measure of fairness." Rather, as we show in the next section, if partisan bias were to be adopted as a key component of a legal test for unconstitutional partisan gerrymandering, the Supreme Court could draw on its jurisprudence in other voting rights areas to establish appropriate constitutional thresholds and to evaluate empirical evidence for unconstitutional effects in a fashion that is readily judicially manageable.
Having an unambiguous, generally accepted, and easy to apply definition of partisan fairness in redistricting will make devising a legal standard for unconstitutional partisan gerrymandering much more straightforward.

A final and related source of confusion about the partisan bias methodology is the claim made by the State Appellees in their Brief in Jackson v. Perry, at p. 47 that "adopting an overall goal of 'symmetry' would require constructing maps that take no account of other, more traditionally meaningful redistricting values." That claim is flatly wrong. As we discuss in Section IV, by drawing on well-established approaches in other domains of voting rights case law, standard redistricting criteria can easily be incorporated into legal review of partisan gerrymandering claims, especially as they involve consideration of defenses against a finding of partisan bias that rely on the State's claimed need to satisfy standard districting criteria, and issues of constructing judicial remedies if unconstitutional partisan gerrymandering is found. More generally, we would note that the fact that there are competing legitimate (or even constitutionally grounded) criteria which courts must balance when considering partisan gerrymandering is no different from the task confronting courts in many other areas of constitutional and statutory jurisprudence involving various aspects of the Bill of Rights or the Civil War Amendments.

75 Justice Souter's opinion in Vieth, 158 L. Ed. 2d 546, at 602 , cites to various sources supporting the view that partisan gerrymandering has been made easier given modern computer technology (e.g., R. Pildes, Principled Limitations on Racial and Partisan Restricting, 106 Yale L. J. 2505, 2553-2554 (1997) ("Recent cases now document in [microscopic] detail the astonishing precision with which redistricters can carve up individual precincts and distribute them between districts with confidence concerning the racial and partisan consequences"); and Morrill, "A Geographer's Perspective," in Political Gerrymandering and the Courts 213-214 (B. Grofman ed. 1990) (noting that gerrymandering can produce "high proportions of very safe seats").).

76 In their Brief in Jackson v. Perry, at p. 47.

77 In their Brief in Jackson v. Perry, at 46-47.

${ }^{78}$ Whatever might be our views as citizens, as social scientists, we deliberately chose not to advocate a specific threshold test for egregious partisan gerrymandering, since we regard setting this threshold as a matter of constitutional interpretation best left to the courts.

${ }^{79}$ In their Brief in Jackson v. Perry, at p. 46. 


\section{OPTIONS IN SETTING LEGAL THRESHOLDS FOR PRIMA FACIE UNCONSTITUTIONAL PARTISAN BIAS}

We have argued that the now well-developed statistical methodology used in the scholarly literature to measure partisan bias and electoral responsiveness can readily form the evidentiary basis for a metric that can be used to measure partisan gerrymandering effects, ${ }^{80}$ and it can allow courts to craft a "clear, manageable, and politically neutral" measure of "the particular burden a given partisan classification imposes on representational rights." 81 The level of partisan bias (which can be calculated as the difference between the seat shares that each of the two parties would receive if they each had received identical shares of the vote) can be used to evaluate the extent to which "each political group in a State [has] the same chance to elect representatives of its choice as any other political group." 82

However, as we have emphasized earlier, while partisan bias can provide the basis of measuring the magnitude of inequality of treatment, the issue of when inequities rise to the level of a constitutional violation is a quite distinct question. In this section we focus on five potential approaches to craft a judicially manageable standard for unconstitutional partisan gerrymandering that build on the concept of partisan bias to identify legal thresholds for prima facie evidence of equal protection violations. Each of these approaches can be seen as straightforward adaptations of constitutional or statutory standards that the Supreme Court has adopted in other areas of voting rights case law. The latter two arise from ideas in Justice Kennedy's opinion in LULAC.

Require plans with as little partisan bias as practicable

The Supreme Court could adopt a rule that requires plans that create as little partisan bias as practicable. Such a rule could be adapted from the Supreme Court's jurisprudence in the area of standards for acceptable deviations from population equality in the context of Congressional districting. In the one-person, one-vote context, the Supreme Court has re- quired zero population deviation for Congressional districts, while still permitting the state to justify minor population deviances by showing a compelling need. ${ }^{83}$ Moreover, the state need only achieve complete population equality "as nearly as practicable." ${ }^{84}$ So long as a state attempts in good faith to create equal districts, the plan passes constitutional muster. ${ }^{85}$

If this were the approach taken by the Court, states would need to make a good-faith effort to achieve as little partisan bias as possible. States can comply with the "as little as possible" rule quite simply. The sophistication of computer mapping technologies allows states to evaluate partisan bias in creating a redistricting plan. States may then attempt to justify deviations from political symmetry by pointing to a legitimate interest such as compactness, respecting municipal boundaries, minority rights, or respecting communities of interest. ${ }^{86}$

Disqualify plans with partisan bias that deviate from symmetry by at least one seat

The Supreme Court could adopt a rule that a plan can be overturned as an unconstitutional partisan gerrymander only if it can be shown that the plan locks in political advantage for one political party of one or more legislative seats as compared to a plan that was symmetric with respect to the parties. Through the use of experts, a plaintiff would have to prove that a map would cause a group to lose at least one seat. Such a rule could be adapted from the Supreme Court's jurisprudence in the area of

\footnotetext{
80 The courts have frequently made use of statistical concepts adapted from the social sciences in devising voting rights standards, e.g., Thornburg v. Gingles, 478 U.S. 30, 55-61, 74-77 (1986) (using statistics to determine the existence of racial bloc voting, a necessary part of any $\S 2$ claim); or Brown v. Thomson 462 U.S. 835 (1983) (measuring the total population deviation to adjudicate one person, one vote claims).

81 Vieth, 541 U.S. 267 at 307-308 (Kennedy, J., concurring in the judgment).

${ }^{82}$ Davis v. Bandemer, 478 U.S. at 124.

83 See, e.g., Karcher v. Daggett, 462 U.S. 725, 740-41 (1983).

${ }^{84} \mathrm{Id}$. at 730.

${ }^{85} \mathrm{Id}$. at $730-31$.

${ }^{86}$ Cf. id. at 740 .
} 
standards for minority vote dilution in the context of Section 2 of the Voting Rights Act. ${ }^{87}$

Disqualify only those plans with egregious levels of partisan bias (defined in terms of a specified percentage point threshold)

The Supreme Court could adopt a rule setting a standard for egregious gerrymanders, by specifying a threshold level of partisan bias in percentage point terms such that plans which exhibit levels of bias below that threshold are regarded as prima facie constitutional, and which requires that plans with partisan bias above that threshold to be justified in terms of compelling, legitimate, and rational state policies and interests. Such a rule could be adapted from the Supreme Court's jurisprudence in the area of standards for acceptable deviations from population equality in the context of state and local districting. ${ }^{88}$

In this third approach, if the average difference in the seat percentage between the two parties, given an empirically reasonable value of the average district vote, is above a particular threshold (whether it be 3, 5, or 10 percentage points), the plan would be prima facie unconstitutional. For example, suppose the court set the standard at 10 percentage points. In this situation, a plan would not be unconstitutional unless one party could be expected to capture 10 percentage points more seats than the other party even if the two parties received identical shares of the vote. ${ }^{89}$ This unconstitutional level would be reached if the Democrats received $65 \%$ of the seats if they received $55 \%$ of the votes, but the Republican Party received 75\% of the seats given the same $55 \%$ vote share.

Each of the three approaches above is based on a different but easy-to-manage judicial standard, and one that has been applied in other areas of the law. For example, since states know the total population before redistricting, and because application of the one-person, one-vote standard is straightforward, relatively little litigation results. Similarly, whenever a state redistricts and uses existing computer technology so that we can match (past) election outcomes to geographic units, measuring prospectively or retrospectively the partisan bias of a plan is also straightforward..$^{90}$
Disqualify only those plans that (can be expected to) translate a minority of the votes into a majority of the seats

In general, it is not possible to directly infer the existence of partisan bias from the fact that a given party receives a lower seat share than its vote percentage. That is because, as we have pointed out earlier, seats-votes relationships are a combination of electoral responsiveness and partisan bias, the two components of which must be jointly estimated by appropriate statistical methodology. Only statistical analyses that make uses of election outcomes in particular units of geography aggregated to the level of the individual districts can give us the appropriate measurements of these key parameters.

But there is one situation in which it is possible simply by comparing vote share and seat share to reliably infer partisan bias in an election that has already occurred, namely a two party contest in which a party with a majority of the votes gets less than a majority of the seats. As long as this difference cannot be ruled out on the basis of random variability that is not likely to persist in subsequent elections (a problem easily avoided with the methods outlined above), we can think of such a situation

${ }^{87}$ Cf. Thornburg v. Gingles, 478 U.S. at 44-46 (imposing a test for justiciability under $\S 2$ of the Voting Rights Act, 42 U.S.C. $\S 1973$, that requires a showing that the minority population is "sufficiently large and compact to constitute a majority in a single-member district" so there exists a potential remedy plan with at least one more reasonably compact district in which minorities have a realistic opportunity to elect candidates of choice than is found in the challenged plan).

${ }^{8}$ Cf. Brown v. Thompson, 462 U.S. 835 (1983) (above 10\% population deviation is prima facie unconstitutional for state legislative districts); $i d$. at 852 (outlining test for determining when a plan is unconstitutional).

${ }^{89}$ This ten percentage point range threshold would correspond to a bias of five percentage points in that, if one party gets five percentage more and one party five percentage points less than the symmetric outcome, this gives us a difference between the seat shares of the parties (relative to symmetry) of ten percentage points.

${ }^{90}$ Cf. Karcher at 733 (noting that in 1983, "[t]he rapid advances of computer technology and education during the last two decades make it relatively simple to draw contiguous districts of equal population and at the same time to further whatever secondary goals the State has.").

${ }^{91}$ As far as we are aware, the majoritarian criterion is first proposed-but not under that name-in Bernard N. Grofman, Criteria for districting: A social science perspective, 33(1) UCLA Law Review 77-184, Table 1, p. 174 (1985). 
as violating a fundamental tenet of majority rule which we may call the majoritarian criterion..$^{91}$

In such a situation there must be partisan bias against the party winning the majority of the votes. This situation may be thought of as distinct from other examples of partisan bias because majoritarian ideas are so deeply engrained in our political system. It somehow seems more heinous to prevent a majority from exercising its mandate, then merely to exaggerate the size of a majority. Moreover, exaggerating the size of the majority is virtually inevitable under pluralitybased legislative elections because of electoral responsiveness values above one (the bonus effect). As we have previously remarked, Justice Kennedy, in his LULAC opinion (at p. 12) views these two types of outcomes (vote majorities into seat minorities; vote majorities into even larger seat majorities) as conceptually distinct. He also clearly regards the former case as the potentially more serious violation of equal protection in terms of the impact of partisan bias in generating the outcome. ${ }^{92}$

If we take this distinction seriously, and regard only the former type of outcome as (potentially) constitutionally violative it suggests a distinct (prima facie) test for when partisan gerrymandering rises to the level of an unconstitutional violation, namely that the level of partisan bias must be such as to (reliably) convert a minority party in terms of votes into a majority party in terms of seats. Because this condition will only rarely be found in situations involving partisan gerrymandering-after all, normally the party which controls the districting is a majority party and it will merely draw plans that will extend the magnitude of its dominance-under this test, even a prima facie finding of unconstitutional partisan gerrymandering might be very rare. Nonetheless, had this standard been in place earlier, however, the evidence reviewed in Justice Kennedy's opinion suggests that the 1991 pro-Democratic gerrymander might have been struck down in mid-decade or later in looking at the results of elections that took place under that plan..$^{93}$ This districting was one whose circumstances could give rise to a violation of the majoritarian criterion because it was a partisan plan drawn by a party in power able to control districting whose leadership was, arguably, aware of the electoral tides running against the party and who sought to preserve that party's dominance through creative gerrymandering. Thus, even

92 In Vieth, Justice Breyer has taken a similar view of the importance of majority representation:

At the same time, these considerations can help identify at least one circumstance where use of purely political boundary-drawing factors can amount to a serious, and remediable, abuse, namely the unjustified use of political factors to entrench a minority in power. By entrenchment I mean a situation in which a party that enjoys only minority support among the populace has nonetheless contrived to take, and hold, legislative power. By unjustified entrenchment I mean that the minority's hold on power is purely the result of partisan manipulation and not other factors. These "other" factors that could lead to "justified" (albeit temporary) minority entrenchment include sheer happenstance, the existence of more than two major parties, the unique constitutional requirements of certain representational bodies such as the Senate, or reliance on traditional (geographic, communities of interest, etc.) districting criteria.

The democratic harm of unjustified entrenchment is obvious. As this Court has written in respect to popularly-based electoral districts:

"Logically, in a society ostensibly grounded on representative government, it would seem reasonable that a majority of the people of a State could elect a majority of that State's legislators. To conclude differently, and to sanction minority control of state legislative bodies, would appear to deny majority rights in a way that far surpasses any possible denial of minority rights that might otherwise be thought to result. Since legislatures are responsible for enacting laws by which all citizens are to be governed, they should be bodies which are collectively responsive to the popular will." Reynolds, 377 U.S. at 565, 84 S. Ct. 1362, 12 L. Ed. 2d 506.

Vieth, at 360 .

93 Justice Kennedy reports (at p. 4) that "[t]he 1991 plan 'carefully constructs Democratic districts "with incredibly convoluted lines" and packs "heavily Republican" suburban areas into just a few districts.' " Henderson $v$. Perry, 399 F. Supp. 2d 756, 767 n. 47 (2005); quoting M. Barone and R. Cohen, Almanac of American Politics, p. 1510 (2003). His opinion notes further that "Voters who considered this unfair and unlawful treatment sought to invalidate the 1991 plan as an unconstitutional partisan gerrymander, but to no avail. See Terrazas v. Slagle, $789 \mathrm{~F}$. Supp. 828, 833 (W.D. Tex. 1992); Terrazas v. Slagle, 821 F. Supp. 1162, 1175 (W.D. Tex. 1993). The 1991 plan realized the hopes of Democrats and the fears of Republicans with respect to the composition of the Texas congressional delegation. The 1990's were years of continued growth for the Texas Republican Party, and by the end of the decade it was sweeping elections for statewide office. Nonetheless, despite carrying $59 \%$ of the vote in statewide elections in 2000, The Republicans only won 13 congressional seats to the Democrats; 17. Henderson, supra, at 763." 
under this remarkably strict standard suggested by some of Justice Kennedy's observations about partisan bias, there is no reason to think that partisan gerrymandering would remain a legal "dead letter." 94

Disqualify only those plans whose partisan bias is both severe and greater than that in the plan being replaced

A central issue with respect to any standard for equal protection is the specification of a baseline against which equal treatment is to be judged. As long as the U.S. makes uses of plurality-based single seat districts for its most important elections, the issue of determining a baseline will be with us. For two party compe- tition, a good way to specify such a baseline is to look at deviations from symmetry in translating votes into seats at the point where each party receives exactly 50 percent of the vote. Equal treatment is this context implies that each party would get an (approximately) equal share of the seats. Another approach, suggested by ideas in Justice Kennedy's opinion, is to compare the magnitude of the deviations from partisan symmetry found in the challenged plan with that found in its immediate predecessor (or predecessors). A possible test based on this idea would give us a prima facie case for unconstitutional partisan gerrymandering only if the plan's deviations from symmetric treatment were both severe and more egregious than those in previous plans. ${ }^{95}$
${ }^{94}$ Also we would emphasize that this test directly involves what we may think of as a special case application of the symmetry standard.

95 Justice Kennedy's opinion (at pp. 4-6) seems to indicate that he regarded the LULAC challenge to the 2003 Texas congressional plan as failing this test. For example, at p. 5, he quotes the Henderson court's views that the "practical effect" of the 2001 Balderas court-drawn plan, was to "leave the 1991 Democratic gerrymander largely in place as a 'legal plan.'" Henderson v. Perry, 399 F. Supp. 2d 756, 763 (2005). And, as we earlier noted, Justice Kennedy apparently views the 1991 plan, with its perceived perpetuation of a minority party in power, as legally more heinous than what he sees as the 2003 plan's exaggeration of the voting strength of a majority party. We would point out, however, that there is dispute about the partisan nature of the 2001 plan. In his opinion (at pp. 5-6), Justice Stevens disputes Justice Kennedy's characterization of the 2001 plan, and argues that it was, in fact, a politically neutral plan. Thus, in Justice Stevens' view, the comparison that Justice Kennedy makes between a 2001 plan that is essentially the legacy of a blatant Democratic gerrymander and a 2003 plan biased in favor of Republicans is inapposite. Justice Stevens also quotes extensively to the Henderson court's characterizations of the 2001 plan, and reminds us (at p. 6) that, at the conclusion of its line-drawing, the Balderas court believed that it had fashioned a map that was "likely to produce a congressional delegation roughly proportional to the party voting breakdown across the state." App. to Juris. Statement, at 209a. In this context we might note that neither Democrats nor Republicans challenged the Balderas plan as a partisan gerrymander. Justice Stevens (at p. 6) goes on to suggest, however, that insofar as the 2001 plan was biased, the bias was in a pro-Republican and not a proDemocratic direction. On that page he quotes the Session court for the proposition that: "reflecting the growing strength of the Republican party, the District Court's plan, 1151 , offered that party an advantage in 20 of the 32 congressional seats. See Session, 298 F. Supp. 2d, at 471 (de- scribing 1151C)." Justice Stevens (id.) also quotes the view of the state's expert in the litigation involving the Balderas plan, Professor Ronald Keith Gaddie, that the Balderas plan was not biased in favor of Democrats, and that it was "'[m]aybe slightly biased' in favor of Republicans." App. 224. Justice Stevens then goes on to note (at p. 6): "In the 2002 congressional elections, however, Republicans were not able to capitalize on the advantage that the Balderas plan had provided them. A number of Democratic incumbents were able to attract the votes of ticket splitters (individuals who voted for candidates from one party in statewide elections and for a candidate from a different party in congressional elections) and thus won elections in some districts that favored Republicans. As a result, Republicans carried only 15 of the [32] districts drawn by the Balderas court." In the footnote following (n. 9 at pp. 6-7) Justice Stevens further observes: "It was apparently these electoral results that later caused the District Court to state that the practical effect of Plan 1151C 'was to leave the Democratic party gerrymander largely in place,' " Henderson at 768 n. 2-the language quoted in Justice Kennedy's opinion. But in that footnote Justice Stevens goes on to further argue that "the existence of ticket-splitting voters hardly demonstrates that plan 1151C was biased in favor of Democrats." The apparent factual disagreement between Justice Stevens and Justice Kennedy reflects the different ways in which each treated incumbency advantage. In effect, the analyses relied on by Justice Stevens looked at the plan as if all seats were open seats, while Justice Kennedy paid attention to the effects of Democratic incumbencies in seats that might otherwise be held by Republicans. The JudgeIt program allows courts to evaluate plans either with or without taking incumbency advantage into account. Which is the correct approach in our view is, ultimately, a legal judgment. However, we would note that incumbents may retire or be swept away by a strong electoral tide if their safety margins are cut too thin. See B. Grofman and T. Brunell, "Art of the Dummymander," 2005 op cit. 
Just as most of the prima facie tests for gerrymandering that we identified above are inspired by other areas of voting rights case law (e.g., standards used for one person, one vote), so this latter test could be thought of as inspired by how courts have often dealt with the issue of compactness when it arises in cases involving state constitutional requirements. While there are many measures of compactness, for none of them is there a clear metric to determine what is egregiously illcompact. ${ }^{96}$ In coping with this problem, courts frequently compare the compactness of a given plan (or given districts) to that of competing plans (or districts within the same or other plans) or to compactness measurements in a predecessor plan. Here, analogously, what we would be doing is comparing the (absolute) magnitude of deviation from partisan symmetry in a challenged plan from what was found in earlier plans-usually plans that had been held to be constitutional. ${ }^{97}$

\section{$* * *$}

We take no position on which of these five approaches is constitutionally most appropriate or which best fits the notion of "egregious" unconstitutionality first enunciated in Bandemer. ${ }^{98}$ As noted earlier we regard that determination as a legal issue that is outside the purview of this article, and a choice the Supreme Court can and should make. Whichever of these legal thresholds is adopted, it will be straightforward to determine if a constitutional violation has occurred (at least prima facie), and states and those drawing the lines in each state will know in advance whether any plan they propose is likely to pass court review.

For purposes of empirical calibration, we would note, however, that studies of past partisan gerrymanders have shown that most gerrymanders have a partisan bias of 1-3 percentage points in favor of the party controlling the redistricting. This effect is typically persistent over the decade following the redistricting, and accounts for measurable differences in the representation of the state's population in the state legislature or Congress. Occasionally, the difference is greater than 5 percentage points, and only in rare cases does a gerrymander results in a difference of over 10 percentage points. ${ }^{99}$

\section{USING PARTISAN BIAS AS A COMPONENT OF A JUDICIALLY MANAGEABLE STANDARD FOR DETECTING AND MEASURING UNCONSTITUTIONAL PARTISAN GERRYMANDERING}

Section I of this article demonstrates that partisan symmetry is a substantive definition of fairness in districting that commands general assent in the scholarly community. Section II shows how measuring the deviation of an electoral system from partisan symmetry, to determine partisan bias, is at least as empirically straightforward and conceptually clear as the concepts used to evaluate districting plans

96 See Richard G., Niemi, Bernard Grofman, Carl Carlucci and Thomas Hofeller, Measuring compactness and the role of a competent standard in a test for partisan and racial gerrymandering, 52(4) Journal of Politics 1155-1181 (1990).

97 Cf. Hofeller, Thomas and Bernard Grofman, "Comparing the compactness of California congressional districts under three different plans, 1980, 1982 and 1984," in Bernard Grofman (ed.), Political Gerrymandering and the Courts (NY: Agathon Press, 281-288 1990).

98 See Vieth, 541 U.S. at 316 (Kennedy, J., concurring in the judgment).

99 Andrew Gelman \& Gary King, Enhancing Democracy Through Legislative Redistricting, 88 Am. Pol. Sci. Rev. 541, 546 fig. 2 (1994) (showing 15 states over a twenty-year period where the partisan bias rarely exceeded $5 \%$ and never exceeded 10\%); Robert X. Browning \& Gary King, Seats, Votes, and Gerrymandering: Estimating Representation and Bias in State Legislative Redistricting, 9 Law \& Pol. 305, 318 (1987) (examining the Indiana plan in the 1980s that was the subject of Davis v. Bandemer and concluding that the House plan had a bias of $6.2 \%$ while the Senate plan had a bias of $2.8 \%$ ); King \& Browning, Democratic Representation, 81 Am. Pol. Sci. Rev. at 1262 Fig. 5 (showing bias in all states, with the plurality showing little if any bias, the vast majority falling within 5 percentage points, a few between 5 and 10, and even fewer above 10); id. at 1269 (listing bias figures for all states and showing only one state with a bias of above 10 percentage points); Gary W. Cox \& Jonathan N. Katz, Elbridge Gerry's Salamander: The Electoral Consequences of the Reapportionment Revolution 57-59 (2002) (finding extreme cases of gerrymandering at as much as 8 percentage points). We might also note that in the supposedly bipartisan gerrymander Connecticut in the early 1970s that was at issue in Gaffney v. Cummings, 412 U.S. 735 (1973), Gary King, Representation through Legislative Redistricting: A Stochastic Model, 33 Am. J. Pol. Sci. 787,814 (1989) finds partisan bias of $3 \%$. 
found in some other areas of voting rights and which the Supreme Court have found to be judicially manageable. ${ }^{100}$

But, while social science can offer a definition of partisan fairness and a methodology for calculating partisan bias which is well-established and whose fundamentals are essentially undisputed within the political science literature, only the courts can devise an appropriate constitutional standard for egregious and unconstitutional partisan gerrymandering, and set appropriate thresholds as to evidentiary burdens. In Section III of this article we have shown how courts (building on what the Supreme Court said in LULAC) might draw on ideas from other areas of voting rights case law to set a plausible threshold test for prima facie unconstitutional partisan gerrymandering that makes use of the concept of partisan symmetry (either prospectively or retrospectively). We use this section to contribute to the ongoing debate about exactly how partisan bias can be made part of a broader legal test for unconstitutional partisan gerrymandering. ${ }^{101}$

Looking at the views in LULAC expressed by Justices Souter, Breyer, Stevens and Ginsburg in conjunction with those of Justice Kennedy, we see clear signs that such a test can be devised in a fashion that will command a majority of the present members of the Court. We argue that there almost certainly will be a multi-step process in evaluating claims of unconstitutional partisan gerrymandering. We suggest that one key element of such a process would be based primarily on prima facie evidence for violations of some form of partisan symmetry test, and rebuttal thereto based on claims of competing and overriding legitimate considerations.

Moreover, we suggest that issues relevant to the remedy phase of a partisan gerrymandering claim will be somewhat different than issues relevant to the liability phase, and will likely focus on the characteristics of particular districts, even though the level of partisan bias statewide remains central in all phases of the case. Also, while we will argue that there are several characteristics of the concept of partisan bias that give rise to distinctive aspects of its incorporation into a constitutional test for equal protection (see discussion below of dif- ferences between racial gerrymandering and partisan gerrymandering), we also believe that the manageable standards for unconstitutional partisan gerrymandering needed by the Court can draw on parallels with its successful jurisprudence in other domains of voting rights. Finally, we suggest, that issues relating to the satisfaction of traditional districting criteria may be relevant to the issue of partisan intent even if not directly relevant to the issue of partisan effects. Thus, while in our view partisan fairness, and its direct measurement in the form of a symmetry test applied jurisdiction wide, should remain at the heart of any partisan gerrymandering claim, adopting this position does not in any way preclude a look at various specific features of a redistricting plan (or proposed remedies) such as compliance with standard redistricting norms like contiguity or compactness.

We begin our discussion of how the Supreme Court might usefully learn from its own successes in other domains of voting rights case law with "one person, one vote" case law, focusing on one particular case, Brown v. Thomson. ${ }^{102}$ Some key language from Brown (at $\mathrm{p}$. 852) illustrates how, in the context of one person, one vote, the Supreme Court has successfully integrated concepts and measurement, legal rules involving thresholds, and evidence about ancillary factors into a multi-part but nonetheless unified legal approach. In that

100 See, e.g., Shaw v. Reno, 509 U.S. 630, 646-49 (1993) (explaining how to decide whether a race is a preponderant motive, and examining "appearance," among other factors), and Georgia v. Ashcroft, 539 U.S. 461, 480 (2003) (discussing the concept of minority influence and noting that "[t]he ability of minority voters to elect a candidate of their choice is important but often complex in practice to determine").

101 While our expertise is primarily in the social sciences, because we each have served as expert witnesses in many situations where we must use our social science knowledge to address legal issues, in this section we propose several different ways in which the Supreme Court might draw upon the concept of partisan bias to craft a constitutional standard for partisan gerrymandering. We do this by looking at how the Court has already successfully crafted judicially manageable standards in other areas of voting rights.

102462 U.S. 835 (1983). 
case, the court wrote (internal cites included as given):

Our cases since Reynolds have clarified the structure of constitutional inquiry into state legislative apportionments, setting up what amounts to a four-step test.

First, a plaintiff must show that the deviations at issue are sufficiently large to make out a prima facie case of discrimination. We have come to establish a rough threshold of $10 \%$ maximum deviation from equality (adding together the deviations from average district size of the most underrepresented and most overrepresented districts); below that level, deviations will ordinarily be considered de minimis. Ante, at 842-843; Connor v. Finch, 431 U.S. 407, 418 (1977); White v. Regester, 412 U.S. 755, 763-764 (1973).

Second, a court must consider the quality of the reasons advanced by the State to explain the deviations. Acceptable reasons must be "legitimate considerations incident to the effectuation of a rational state policy," Reynolds, supra, at 579, and must be "free from any taint of arbitrariness or discrimination," Roman, supra, at 710. See Mahan v. Howell, 410 U.S. 315, 325-326 (1973).

Third, the State must show that "the state policy urged ... to justify the divergences . . . is, indeed, furthered by the plan," id., at 326 . This necessarily requires a showing that any deviations from equality are not significantly greater than is necessary to serve the State's asserted policy; if another plan could serve that policy substantially as well while providing smaller deviations from equality, it can hardly be said that the larger deviations advance the policy. See, e.g., Kilgarlin v. Hill, 386 U.S. 120, 123-124 (1967); Mahan, supra, at 319-320, 326; Connor, supra, at 420-421.

Fourth, even if the State succeeds in showing that the deviations in its plan are justified by their furtherance of a rational state policy, the court must nevertheless consider whether they are small enough to be constitutionally tolerable. "For a State's policy urged in justification of disparity in district population, however rational, cannot constitutionally be permitted to emasculate the goal of substantial population equality." Mahan, supra, at 326.

This language, as we demonstrate below, provides a number of important clues as to how to craft a manageable standard for partisan gerrymandering. Moreover, the Brown v. Thomson multi-part approach will allow us, in large part, to reconcile the seemingly incompatible views of the four dissenting justices in Vieth.

First, it identifies a specific threshold for when a one person, one vote violation becomes prima facie unconstitutional. Second, it recognizes that, even though one person, one vote issues are fundamentally about population equality, other considerations can also play a role in deciding such cases. Third, it allows for a process of burden shifting. In the initial phase of the case, the key element for the plaintiffs is to show a sufficiently large (legally significant) deviation from one person, one vote. Once that is shown, the burden shifts to the defendant jurisdiction to make a case that the deviations in question are legitimated by a rational state purpose. Fourth and finally, that evidence is, in turn, rebuttable, especially as to whether the state's justifications are compelling ones given the nature and magnitude of the demonstrated deviation from population equality.

Of course, we are not proposing that the Brown v. Thomson standard be adapted "as is" with partisan bias merely substituted for deviation from equal population. For example, as we showed in Section III, the voting rights case law suggests several different ways courts might specify a threshold as to when the level of partisan bias was constitutionally relevant. ${ }^{103}$ Similarly, we regard the last three ele-

\footnotetext{
103 Our discussion of threshold standards in this previous section focused primarily on the first part of the four part test for one person, one vote violations laid down in Brown v. Thomson 462 U.S. 835 (1983) from which we quote above, namely the part which establishes a threshold for identifying a potential one person, one vote constitutional violation.
} 
ments of the Brown test as suggestive, rather than determinative, of how to proceed vis-à-vis partisan gerrymandering. The key, as illustrated in the long quote from Brown v. Thomson with which we began this section, is the recognition that identifying a legally relevant concept, showing how to measure it empirically, and specifying a threshold for which it becomes legally relevant, while necessary conditions for crafting a legal standard in the context of voting rights claims, do not end legal deliberations. Other ancillary considerations may come into play, especially at the remedy phase of a trial, or in attempts to justify grounding of a plan in a legitimate and compelling state interest, or in assessing whether partisans have intentionally gone well beyond "normal" redistricting in pursuit of partisan advantage to engage in deliberate egregious manipulation of district boundaries. Relatedly, both statewide and constituency specific characteristics of a plan may also enter into a determination of the legitimacy of choices made by line-drawers in terms of establishing impermissible intent and/or in terms of justifying their choices as rational state action.

Below we will consider how ideas from the last three components of the Brown $v$. Thomson approach to the crafting of a legal standard to establish a violation of constitutionally protected voting rights, and that of other voting rights approaches, might be combined in the context of partisan gerrymandering claims.

\section{Integrating a symmetry standard with compactness and other traditional districting criteria}

The role of compactness and maintenance of previous boundaries in effects-based standards of unconstitutional partisan gerrymandering. Criteria such as compactness and respect for existing political boundaries are often used as proxies for partisan gerrymandering, but they are typically not very good proxies. One of us has previously emphasized the important point made in the plurality opinion in Vieth that "packing and cracking, whether intentional or not, are quite consistent with adherence to compactness and respect for political subdivision lines."104 The fundamental issue in partisan gerrymandering cases in terms of effects is whether a districting plan unfairly burdens the representational rights of a particular political group, not whether or not districts look pretty.

Moreover, partisan bias is certainly not the only issue in gerrymandering cases. As Justices Stevens and Souter argued in Vieth, satisfying compactness considerations and other common districting criteria, such as respect for existing jurisdictional boundaries or not splitting communities of interest, are often important in and of themselves. ${ }^{105}$ That is, while violation of neutral standards such as compactness and contiguity are not, in and of themselves, direct evidence of partisan gerrymandering effects, ${ }^{106}$ using them can satisfy other legal rules and requirements and as such can enter into legal review of claims of the legality of a redistricting plan, once a prima facie level of unconstitutional partisan bias has been established. ${ }^{107}$ This can

104 Vieth, 158 L. Ed. 2d, at 565. See Bernard Grofman, Criteria for Redistricting: A Social Science Perspective, 33 U.C.L.A. Law Review 77-184, 88-93 (1985). Also, as legislators employ more and more sophisticated tools for redistricting, they can comply quite easily with some of these objective criteria while still burdening the right to fair and effective representation through political gerrymandering.

105 See Vieth, 541 U.S. at 335 (Stevens, J., dissenting); id. at 347-48 (Souter, J., dissenting). See also Davis v. Bandemer, 478 U.S. 109, 165 (1986) (Powell, J., dissenting) (looking to the "configurations of districts, the observance of political subdivision lines, and other criteria that have independent relevance to the fairness of districting").

106 As we have previously emphasized, only partisan bias is a direct measure of partisan gerrymandering effects.

107 Other districting criteria, such as similar treatment of each party's incumbents, may also be relevant. Those doing gerrymandering will often seek to eliminate the seats of one or more incumbents of the other party by drastic redrawing of districts lines or by pairing incumbents in the same district. The exact way in which incumbent pairings and redrawing of lines to affect incumbents of one party more than incumbents of the other party can impact on partisan bias is a complex topic, and best left to case-specific analysis. Suffice it to note that in the contemporary U.S., in congressional and legislative election in virtually any constituency, on average, incumbents run better than do candidates of the same party who are not incumbents. Numerous studies have been done of the magnitude of this incumbency advantage. See e.g., Andrew Gelman and Gary King, Estimating Incumbency Advantage Without Bias, 34(4) Am. J. Pol. Sci. 1142-1164 (November, 1990) <http://gking.harvard.edu/files/abs/inc-abs.shtml $>$. However, since incumbents, per se, have no legal "right" to their seats, the legal relevance for partisan gerryman- 
happen in two different ways: (a) when the burden shifts to the state to justify the level of partisan unfairness found in a plan, and the state argues that features of the plan that led to partisan bias were necessitated by the state's compliance with neutral districting principles such as compactness (cf. part 2 through 4 of the fourpart test from Brown v. Thomson quoted at the beginning of Section IV), ${ }^{108}$ or (b) when we enter the remedy phase of a trial if a court is faced with the task of drawing a plan of its own, or evaluating alternative proposed remedial plans. ${ }^{109}$

The role of standard districting criteria in assessing partisan intent. We would point out that issues relating to the satisfaction of traditional districting criteria, both at the level of individual districts and in terms of overall features of a plan (e.g., average level of compactness, number of unnecessary crossings of political subunit boundaries) may be directly relevant to the issue of partisan intent even if not directly relevant to the issue of partisan effects. In Bandemer, the Supreme Court plurality regarded proof of intent to achieve partisan advantage as at best a minor and probably even an irrelevant part of a partisan gerrymandering claim, because the partisan concerns of line drawers who were placed by the political situation in a position to advantage their partisan cause via redistricting could more or less be taken for granted. But even if we grant that fact, exactly how legislators seek to achieve partisan advantage can still be relevant to determining intent to weight partisan considerations above all others to a constitutionally impermissible degree.

Here an analogy between redistricting and boxing may be helpful. In boxing, we take it for granted that boxers are seeking to knock each other's heads off, yet we still distinguish between a legitimate knockdown and one caused by a low blow. ${ }^{110}$ A review of the features of a plan in terms of standard districting criteria (both at the level of individual districts and in the plan as a whole) can allow courts to assess intent so as to distinguish "normal" redistricting in pursuit of partisan advantage from cases where partisans engage in deliberately inappropriate and egregious manipulation of district boundaries-i.e., have sought to win by the redistricting equivalent of an impermissible low blow. In this context, Justice Stevens suggests in his opinion in LULAC (at pp. 30-32) multiple violations of standard redistricting criteria, coupled with other indicia that point to clear and unchecked partisan motive, may be interpreted as evidence that unconstitutional intentional partisan gerrymandering is going on.

But, in our view, we would not need to get to issues of intent until we had established that a "knockdown" (i.e., a magnitude of partisan bias that, on its face, rises to the level of a constitutional violation) had occurred. Only then would we need to consider the constitutional "legitimacy" of that knockdown in terms of factors such as motive. By leaving intent and other issues having to do with the shapes of the districts until a later stage if the inquiry-a stage that would not even be reached if there was not dering claims of party-specific differences in the treatment of incumbents remains an open question. Justice Stevens (at n. 11, p. 28), uses the "placing of two incumbents of the same party into a single district," and the "number of districts that have been cracked in a manner that weakens an opposition party incumbent" as two of his eight indicia of partisan gerrymandering. Bernard N. Grofman, Criteria for Redistricting: A Social Science Perspective, 33 U.C.L.A. Law Review 77-184, 117 (1985), was one of the first studies to call attention to this incumbentrelated aspect of efficient partisan gerrymandering-one which is still neglected in many studies of this topic. Grofman used it as one of a dozen criteria he identified that might be indicative of gerrymandering.

108 Indeed, Justice Stevens who sees compactness as serving "important values in the districting process," (LULAC,
126 S. Ct. at 2646), takes the very strong position that "a State that creates more compact districts should enjoy a safe harbor from partisan gerrymandering claims" (id.). ${ }^{109}$ Later in this section we will consider how neutral districting criteria play a somewhat different role in partisan gerrymandering cases than they do in other areas of voting rights case law.

${ }^{110}$ We are indebted to A Wuffle (personal communication, April 1, 2005) for suggesting this analogy. (A Wuffle, although not referred to by name in the decision, is best known to the Supreme Court as the author of the poetic pastiche about North Carolina's $12^{\text {th }}$ congressional district quoted in Justice Kennedy's majority opinion in Miller. v. Johnson, 515 U.S. 900 (1995), 132 L. Ed. 2d 762 at 796: "Ask not for whom the line is drawn; it is drawn to avoid thee."). 
a clear legal determination of a level of partisan bias that met some prima facie standard of unconstitutionality-the courts considering partisan gerrymandering claims will have their task much simplified and made more manageable in that many partisan gerrymandering claims are likely to be thrown out at a very early stage in the proceedings.

\section{Statewide versus district-specific measures of gerrymandering}

Justice Breyer argued in Vieth for a statewide test for partisan gerrymandering while Justice Stevens and Justice Souter (joined by Justice Ginsburg) argued for a more districtspecific approach. In $L U L A C$, however, Justice Stevens, while suggesting both an effects and purpose test of partisan gerrymandering that could apply to a single district (Part IV, pp. 30-32), also proposed an effects test for statewide partisan gerrymandering (Part III at n. 11, p. 28). ${ }^{111}$ In our view as social scientists, in an effects-based inquiry into gerrymandering, both approaches are needed-but at different phases of the inquiry. Thus, with respect to the disagreements among the dissenting justices in Vieth about whether a standard should look statewide or be district-specific, substantial as this disagreement appears to be, we believe that the disagreement can resolved.

To the extent that the Supreme Court adopts partisan bias as a basis for estimating the magnitude of partisan gerrymandering effects, the test would necessarily involve calculations and results about the level of partisan bias in the plan as a whole. However, in reviewing the evidence for partisan gerrymandering, it is perfectly reasonable for courts to look to see whether particular districts in a plan exhibit high levels of "packing" or "cracking,"112 so long as these techniques of gerrymandering have an effect in terms of the deviation from partisan symmetry. Even more importantly, while partisan bias involves calculations for a plan as whole, judicial remedies for egregious partisan gerrymandering may often involve "unpacking" minority party voters and recrafting particular sets of districts ${ }^{113}$ that have been the special targets of gerrymandering efforts. ${ }^{114}$
The legal specificity of a partisan gerrymandering standard

A number of features of partisan competition force the use of different methodologies for defining and measuring partisan fairness than

111 Justice Stevens (Part III, at n. 11, p. 28) identifies eight different indicia: (1) the number of people who have been moved from one district to another, (2) the number of districts that are less compact than their predecessors, (3) the degree to which the new plan departs from other neutral districting criteria, including respect for communities of interest and compliance with the Voting Rights Act, (4) the number of districts that have been cracked in a manner that weakens an opposition party incumbent, (5) the number of districts that include two incumbents from the opposite party, (6) whether the adoption of the plan gave the opposition party, and other groups, a fair opportunity to have input into the redistricting process, (7) the number of seats that are likely to be safe seats for the dominant party, and (8) the size of the departure in the new plan from the symmetry standard." Earlier work by one of the present authors took a similar tack: See Bernard Grofman, Criteria for Redistricting: A Social Science Perspective, 33 U.C.L.A. Law Review 77-184, 88-93 (1985) (identifying twelve prima facie indicators of partisan gerrymandering). That work remains relevant, but we would now suggest that these indicators be taken to be ones that can largely inform us about improper partisan intent and lack of legitimate state purpose while partisan bias be taken to be the sole direct measure of partisan effects, although differential and discriminatory treatment of incumbents of opposite parties may also be relevant herea legal issue which we see as not yet resolved.

112 "Packing" and "cracking" are shorthand terms for two of the fundamental tools of partisan gerrymandering, wasting the votes of one's opponents in districts which they win by huge majorities (packing), and dispersing the votes of one's opponents in districts where these votes will not be efficacious in electing candidates of choice (cracking). In addition, for at-large and multimember constituencies, a basic tool of vote dilution is "stacking," i.e., submerging opposition voters who would be large enough and geographically compact enough to form the majority if they were to located within a single member district into a larger (multi-seat) constituency in which they are a clear minority, and in which their votes will not be efficacious in electing candidates of choice. For example, virtually all of the Justice refer to issues involved in the "cracking" of District \#24, albeit only a minority of them would hold that cracking to be unconstitutional or illegal (see, e.g., Justice Souter's opinion and Justice Stevens' views in Part IV of his opinion).

113 In the language used at some points in several of the LULAC opinions such district specific concerns are "granular."

114 Of course, although these remedies to unconstitutional partisan gerrymandering, and indeed every individual boundary line drawn, involve specific districts, the ultimate criterion for assessing the fairness of a redistricting plan to the political parties and their supporters is at the statewide level. As we described in Section I above, the 
we do for other violations of equal protection, such as the protection of racial groups or determinations of one person, one vote violations. Thus, it will be possible for courts to adopt appropriate tests of partisan bias and to incorporate them into standards for unconstitutional partisan gerrymandering without any necessary need to rethink how the Supreme Court has dealt with equal protection in other domains of voting rights in the light of the tests to be used in this area. Three key distinctions are necessary here.

First, just as we previously showed that the concept of partisan symmetry is only appropriate for competitive situations where there is a potential for a change in partisan outcomes (majority control, in particular) as a result of shifting electoral tides, a concept of "racial symmetry" would not be the appropriate way to evaluate equal protection claims involving racial or ethnic groups with fixed ascriptive characteristics. To evaluate "ethnic group symmetry" we would need to ask what would happen to the seat division between the ethnic groups if a state with, say, $10 \%$ African Americans suddenly became $90 \%$ African American. But that really doesn't make sense. While people regularly change their support for political parties on the basis of candidate qualities, issues, and the performance of incumbents, they do not (or cannot) similarly switch ethnic group memberships. And although immigration, emigration, birth, and death do produce changes in the ethnic composition of a state, these changes tend to be very gradual over time and do not really make applying a symmetry standard to racial categories something that makes conceptual sense. ${ }^{115}$

Second, and relatedly, because, as we noted above, there is no direct analogue for measuring the impact of districting on racial groups to the role that partisan bias plays as a direct measure of partisan gerrymandering effects, we would anticipate a more central role of subsidiary criteria such as geographic compactness in the initial phase of voting rights claims that involve racial impact than is found in the legal review of claims related to partisan gerrymandering. In the racial context, courts have examined the shape and appearance of district lines in order to resolve whether a state was engaging in a racial gerrymander. ${ }^{116}$ Similarly, the shapes of districts as they are related to the geographic concentration of minority group populations and to existing jurisdictional boundaries has been found relevant in cases stemming from Shaw $v$. Reno, ${ }^{117}$ where the issue is inferring whether race has been a preponderant motive in line drawing. ${ }^{118}$ But the role of these subsidiary criteria appear to be much less direct in cases involving partisan gerrymandering since there we have, in partisan bias, a direct measure of the consequences we are most concerned about vis-à-vis fairness and equal treatment.

Third, whether for partisan or for racial groups, we would emphasize that the concept of symmetry is not an appropriate basis for addressing equal protection claims in situations involving pure at-large election systems, since absent voter fraud, symmetry will essentially always be satisfied for such at-large systems. In legality of electoral systems requires rules be applied at the individual district-level. But even after all individuallevel rules are applied, we must look to the representation of the state as a whole to determine fairness to the political parties and their supporters. Fairness to the political parties, partisan gerrymandering, and their measures, partisan symmetry and partisan bias, are by their nature concepts that apply to collections of districts rather than to each district separately. Indeed, democratic representation itself is by its nature a collective concept and that is recognized in the concepts used to understand it, the legal rules that apply to it, and the techniques partisans use to affect it.

115 For racial groups, methodology based on the well-established concept of vote dilution is well-established, where we also look to determine if there is racial polar- ized voting necessary to substantiate a claim that group has shared political interests and political identity that go beyond merely sharing ascriptive characteristics. See Bernard Grofman, Lisa Handley, and Richard Niemi, Minority Representation and the Quest for Voting Equality (New York: Cambridge University Press, 1992). The problems with "racial symmetry" and several other possible absolute standards for fairness to racial groups in redistricting are discussed in Gary King, John Bruce \& Andrew Gelman, "Racial Fairness in Legislative Redistricting," in Classifying by Race 85, 85 (Paul E. Peterson, ed., 1996). 116 See, e.g., Gomillion v. Lightfoot, 364 U.S. 339 (1960). 117 Shaw v. Reno, 509 U.S. 630 (1993).

118 In such cases, of course, establishing racial intent may also require addressing other issues, such as competing claims about legislative motives. 
pure at-large systems (i.e., one where the entire legislature is chosen from two competing partisan slates, with each voter in the entire polity having as many votes to cast as there are seats in the legislature), if voters cast all their multiple votes along partisan lines, thus electing either an entire slate of Democrats or an entire slate of Republicans, changes in partisan vote share can affect partisan balance, but they do not affect either partisan bias or electoral responsiveness. That is because in such pure atlarge systems there can be no partisan bias, since the two parties are treated symmetrically in that each will win $100 \%$ of the seats with a plurality of the votes, and the level of electoral responsiveness in pure at-large systems is effectively infinite in that an infinitesimal change in party vote share from $50 \%$ - to $50 \%+$ will change all the seats and thus change party control.

In contrast, in districted systems that use plurality voting (including both ones where all seats elect a single representatives and ones involving multiple districts from some or all of which different numbers of representatives are elected), changes in partisan vote share can affect both partisan bias and electoral responsiveness. ${ }^{119}$ Thus, the possibility of long-term bias in a districted plan is completely different from what we find in an at-large plan. ${ }^{120}$ In a pure at-large election, if there are only two slates, then, as shown above, bias is normally zero, but electoral responsiveness is huge, because there is either feast or famine-either a party (the one with the majority of the votes polity-wide, however slight an edge they might have) wins all the seats, or it wins none. ${ }^{121}$

\section{Synopsis}

One way to think about the basic ideas in this article about how social science can be useful to the courts in making determinations about partisan gerrymandering is in terms of four different contributions, involving (1) conceptualization, (2) measurement, (3) legal relevance, and (4) legal specificity, respectively.

Conceptualization. We have shown that a widespread consensus exists in the social science literature supporting a specific definition of partisan fairness in legislative redis- tricting in plurality-winner district-based elections based on the concept known as partisan symmetry.

Measurement. The social science literature offers statistically grounded, well accepted, and highly informative methods for measuring the deviation of a redistricting plan from partisan symmetry. The degree of deviation from symmetry of treatment is known as partisan bias, and is easily quantified, and made specific as to direction. Expert witness testimony can readily be obtained about the level of partisan bias, and areas of disagreement

119 The discussion we give above is intended to apply only to districted systems of representation.

${ }^{120}$ The only electoral arrangement that has ever been struck down as unfair to a political party by any federal court was the state-wide (at-large) election scheme for Superior Court judges in the State of North Carolina that was overturned by a district court in Republican Party of North Carolina v. Hunt. Because the empirical and legal issues at stake in Republican Party of North Carolina v. Hunt involved a pure at-large (state-wide) election system, the issues in that case are almost totally distinct from those that apply to the districted elections for which the methodology we describe is intended. That trial court, whose ruling was sharply criticized by the plurality in $V i$ eth (at n. 8), based its judgment about unconstitutional partisan gerrymandering by drawing on an analogy between partisan and racial vote dilution. It found Republican candidates historically experiencing a consistent and pervasive lack of success and exclusion from the electoral process as a whole. But, on appeal, the decision of the district court on how to remedy the unconstitutional vote dilution it found was overturned when the U.S. Court of Appeals took judicial notice of Republican success in electing Superior Court judges statewide in an election that took place very shortly after the district court opinion was announced. The Appeals Court (Republican Party of North Carolina v. Hunt, 1996 U.S. App. LEXIS 2029, No. 94-2410, 1996 WL 60439 (4th Cir., Feb. 12, 1996) (per curiam) (unpublished), judgt. order reported at 77 F.3d 470.) remanded the case for further proceedings. However, the remand was mooted by a decision of the North Carolina legislature to enact new legislation specifying districtbased elections for Superior Court judgeships to be held on a non-partisan basis (Marshall Hurley, attorney for the plaintiffs, personal communication, February 1, 2006). But even if this case had been decided otherwise, and even if had not involved an at-large election, its precedential value would have been very limited since this case initially presented an extreme factual situation, one where no Republican judge had ever been elected statewide in a hundred years.

121 At-large elections have been overturned as unconstitutional in settings where, due to polarized patterns of voting, they have been found, in the totality of the circumstances, to minimize or cancel out the votes of minority voters (see Thornburg v. Gingles, 478 U.S. 30 (1986)). 
among competent experts about the magnitude or durability of partisan bias will be limited to fact-specific issues of a sort that courts regularly deal with in the numerous domains where expert witness testimony is commonly accepted as relevant.

Legal Relevance. The social science concept of partisan bias is relevant to courts seeking to craft legal standards for unconstitutional partisan gerrymandering because it is built on the most basic and common notions of fairness in elections, and because it offers a straightforward and direct way to understand "equal protection" in the context of redistricting and political party competition. Thus, courts can draw on social science evidence in making fact-specific and case-specific legal decisions. Of course, however, the ultimate decisions need to be made by the Supreme Court about exactly what criteria, thresholds, and fundamental legal rules should guide lower courts. ${ }^{122}$

Legal Specificity. The menu of choices available to the Court for defining unconstitutional gerrymandering, although based on ideas of equal protection and fairness, are specific to the domain of partisan gerrymandering and do not necessarily carry over into other domains of election law or legislative redistricting. In particular, measures of symmetry are less relevant in domains where we have racial groups with fixed ascriptive characteristics and for which well-established legal concepts such as minority vote dilution are applicable. ${ }^{123}$

\section{CONCLUDING REMARKS}

"The object of districting is to establish 'fair and effective representation for all citizens.' "124 Partisan bias clearly offers a suitable metric to measure, in at least a preliminary fashion, the "burden a gerrymander imposes on representational rights" ${ }^{\prime 25}$ because it is so clearly rooted in commonsense notions of fairness and equality of treatment, ${ }^{126}$ and because it is directly linked to the measurement of the effects of partisan gerrymandering. It is also a concept that can be clearly measured and about which evidence can be provided by competent social sci- ence testimony. ${ }^{127}$ Now that members of the Supreme Court have singled out the deviation from partisan symmetry as a potential key indicator of partisan gerrymandering (with partisan bias arguably playing a role analogous to the total population deviation in the one person, one vote cases), we anticipate that there will be new partisan gerrymandering challenges brought. But since the bar has clearly been set high, with the Court's refusal to invalidate the Texas congressional plan as an unconstitutional partisan gerrymander, we would not anticipate that there will be many such new challenges. What we would expect, though, is that most new challenges will seek to attract the votes of Justice Kennedy, as a pivotal member of the Court, by basing their legal challenges to plans on results of elections already conducted under that plan rather than on prospective assessments of expected severe long term partisan bias. Either way, redistricters, and lawyers

122 Such determinations will, of course, be based on the Supreme Court's own constitutionally- and historicallygrounded jurisprudential analyses.

123 See e.g., Thornburg v. Gingles, 478 U.S. 30 (1986). For social science perspectives on Thornburg $v$. Gingles and the concept of minority vote dilution see Bernard Grofman, Lisa Handley, and Richard Niemi, Minority Representation and the Quest for Voting Equality (New York: Cambridge University Press, 1992, esp. Chaps. 2-3).

${ }^{124}$ Vieth, 541 U.S. at 307 (Kennedy, J., concurring in the judgment) (quoting Reynolds v. Sims, 377 U.S. 533, 565-68 (1964)).

125 Vieth, 541 U.S. at 313 (Kennedy, J., concurring in the judgment).

126 As noted earlier, we take for granted that elections have objective and symmetrical guidelines for determining who wins: It would not be fair if one candidate could win with a plurality of votes but another candidate could win only if $\mathrm{s} /$ he obtained some supermajority of the votes. Fairness requires that the political process treats each candidate equally. The symmetry approach takes this same principle and applies it to political groups (and their supporters) at the statewide or jurisdiction-wide level by estimating the level of partisan bias in a plan.

${ }^{127}$ Moreover, since we propose to limit investigation of partisan gerrymandering claims to situations that are sufficiently competitive that control of a legislature (or of Congress) is potentially at stake, and because we propose measurement criteria the results of which can readily be known in advance, and because we make determination of the magnitude of partisan bias the initial litmus test which will serve as an evidentiary hurdle for plaintiffs to surmount to even be able to bring a case alleging unconstitutional partisan gerrymandering, the approach we advocate will substantially limit the potential for an intrusive judicial presence into an inherently political process about which Justice Kennedy once expressed concern in his opinion in Vieth. 
arguing redistricting cases, would now be well advised to use the best social science methodologies to estimate the degree to which their plan deviates from partisan symmetry.

As we have emphasized throughout this article, the decision to make use of partisan bias as a prima facie measure of deviation from fairness and equality of treatment leaves open many important legal questions. First, courts will need to consider whether the only relevant evidence of partisan gerrymandering comes from elections actually held under a plan or whether prospective evaluations based on past elections in the same geographic areas might also be probative. This is a topic about which we briefly commented in Section II of our article. Second, courts will need to address the question of what is an appropriate legal threshold for a level of partisan bias that would trigger a prima facie claim of violation of equal protection. This is a question for which we identified various possible answers in Section III. Third, courts will need to address how other criteria might enter as relevant at some phase of the trial process. This is a topic on which we commented in Section IV.

Now that the Supreme Court has provided the first real guidance to lower courts about how to think about partisan gerrymandering claims based on Bandemer v. Davis, we anticipate that the case law in the area of partisan gerrymandering will evolve much as it has in other areas of voting rights-namely deliberately but steadily, and with only occasional further intervention by the Supreme Court to clarify inconsistencies that arise among lower court judgments. ${ }^{128}$ The plurality opinion in Vieth quotes from an earlier statement by Bernard Grofman: ("[A]s far as I am aware I am one of only two people who believe that Bandemer makes sense. Moreover, the other person, Daniel Lowenstein, has a diametrically opposed view as to what the plurality opinion means"). ${ }^{129}$ We find nothing to argue with in that statement, but take from it a very different implication than that drawn by the plurality in Vieth. We believe that perhaps the single most important reason that lower courts have not developed a manageable standard for judicial review of partisan gerrymandering claims in the two decades since Bandemer is that Bandemer and subsequent Supreme Court decisions about partisan gerrymandering failed to provide lower courts adequate guidance about the directions along which such standards might develop. ${ }^{130}$ In our view, if we look closely at the various opinions in LULAC, we can see that the Supreme Court has seeded the clouds after this 20 year drought. ${ }^{131}$ We think that, at last,

128 The Court was warned by Justice Frankfurter not to enter the "political thicket" of reapportionment because it would be unable to craft manageable standards or avoid choosing between competing models of representation. Yet, if we look at how "one person, one vote" standards have actually evolved, this is arguably the area of voting rights case law which is the clearest both in terms of the signals it sends to legislatures as to what they need to do to meet a constitutional test, and to courts as to what they need to do in reviewing challenges based on population inequalities. Early cases such as Reynolds v. Sims did not settle the exact threshold for when unequal population rises to the level of a constitutional violation. Yet, once the Supreme Court determined the general standards for population equality in Reynolds v. Sims, 377 U.S. at 377, and Wesberry v. Sanders, 376 U.S. at 8, subsequent cases simply became legal arguments about exactly what level of population deviation was unconstitutional in given circumstances. Larios v. Cox, 305 F. Supp. 2d 1335 (2004), provided a further complexity, but arguably, even that decision was foreshadowed in earlier one person, one vote cases.

129541 U.S. at 283, (quoting Bernard Grofman, An Expert Witness Perspective on Continuing and Emerging Voting Rights Controversies, 21 Stetson L. Rev. 783, 816 (1992)).

${ }^{130}$ Cf. Vieth, 541 U.S. at 312 (Kennedy, J., concurring in the judgment) (suggesting that no manageable standard developed after Davis v. Bandemer because lower courts could do nothing except follow that decision); $i d$. at 344-45 (Souter, J., dissenting).

131 The only real alternative explanation for the failure of courts to ever find an example of an unconstitutional partisan gerrymander in the nearly two decades since Bandemer was decided is the one offered by UCLA Law Professor Daniel Lowenstein in an article, Vieth's Gap: Has The Supreme Court Gone From Bad To Worse On Partisan Gerrymandering? forthcoming in 2006 in the Cornell Journal of Law and Public Policy. Professor Lowenstein asserts that the plurality opinion in Vieth is wrong in claiming partisan gerrymandering to be nonjusticiable due to a lack of a clear and manageable standard. In his view, Bandemer offers such a clear and legally manageable standard, as shown by the results in the eighteen cases where lower courts were asked to apply it. In Lowenstein's view, Bandemer required a showing that a political party had been subject to the same level of discrimination as once occurred with racial minorities-a total exclusion from politics. In his view, since none of the eighteen cases where lower courts failed to find an unconstitutional partisan gerrymander involved situations rising to this level of discrimination, all these cases were thus properly decided under a judicially manageable standard. Of course, such an interpretation simply makes Bandemer a dead letter de facto instead of de jure. 
there can now be a non-trivial probability of rain, and as a result to a new flowering of American democracy less affected by the ills of partisan gerrymandering. It will now be up to lower courts in future cases to make concrete the ideas about tests for partisan gerrymandering found in $L U L A C$.
Address reprint requests to: Gary King 1737 Cambridge Street Harvard University Cambridge MA 02138

E-mail: King@harvard.edu 


\section{REDDY}
AU1
Please confirm contact information 